\title{
Vogt-Koyanagi-Harada Disease and Birdshot Retinochoroidopathy, Similarities and Differences: A Glimpse into the Clinicopathology of Stromal Choroiditis, a Perspective and a Review
}

\author{
Ähnlichkeiten und Unterschiede zwischen 2 stromalen \\ Choroiditiden: Morbus Vogt-Koyanagi-Harada versus \\ Birdshot-Retinochoroiditis
}

\section{(ㄷ) (1) (우 $\ominus$}

Authors

Sina Elahi ${ }^{1,2}$, Carl P. Herbort jr. ${ }^{2}$

Affiliations

1 Ophthalmology, Clinique de Montchoisi, Chemin des Allinges, Lausanne, Switzerland

2 Retinal and Inflammatory Eye Diseases, Centre for Ophthalmic Specialized Care (COS), Rue Charles Monnard 6 , Lausanne, Switzerland

\section{Key words}

birdshot retinochoroiditis, Vogt-Koyanagi-Harada disease, stromal choroiditis, indocyanine green angiography, immunosuppressive therapy

\section{Schlüsselwörter}

Birdshot-Retinochoroiditis, Morbus Vogt-Koyanagi-Harada, stromale Aderhautentzündung, Indocyaningrünangiografie, immunosuppressive Therapie

$\begin{array}{ll}\text { received } & 21.9 .2018 \\ \text { accepted } & 5.12 .2018\end{array}$

Bibliography

DOI https://doi.org/10.1055/a-0829-6763

Published online 19.3.2019 | Klin Monatsbl Augenheilkd 2019; 236: 492-510 @ Georg Thieme Verlag KG Stuttgart . New York | ISSN 0023-2165

Correspondence

Dr Carl P. Herbort jr.

Retinal and Inflammatory Eye Diseases, Centre for Ophtalmic Specialized Care (COS)

Rue Charles Monnard 6, 1003 Lausanne, Switzerland

Phone: + 41216431512

cph@herbortuveitis.ch

\begin{abstract}
The purpose of this work was to give a comprehensive and updated review on two primary stromal choroiditis entities, Vogt-Koyanagi-Harada disease (VKH) and birdshot retinochoroiditis (BRC). Their appraisal has become much more precise thanks to new investigational methods, such as indocyanine green angiography (ICGA) and enhanced depth imaging optical coherence tomography (EDI-OCT), which give substantially improved imaging access to the choroid. In this review, we focus on the crucial changes brought by this progress in the understanding, diagnosis, and management of these disorders. Application of these methods makes it possible to reach an early diagnosis, therefore allowing early treatment, which has led to a profound improvement in outcomes when compared to previous management.
\end{abstract}

\section{ZUSAMMENFASSUNG}

Zweck dieser Arbeit war es, einen umfassenden und aktualisierten Überblick über 2 stromale Aderhautentzündungen (Choroiditis), Morbus Vogt-Koyanagi-Harada (VKH) und Birdshot-Retinochoroiditis (BRC), zu geben. Die Wahrnehmung von diesen 2 Aderhautentzündungen ist in der letzten Zeit viel präziser geworden dank neuer Investigationsmethoden wie Indocyaningrünangiografie (ICGA) und „Enhanced Depth Imaging Optical Coherence Tomography“ (EDI-OCT). Diese Methoden erlauben einen wesentlich besseren bildgebenden Zugang zu den Aderhautstrukturen. In diesem aktualisierten Überblick konzentrieren wir uns speziell auf die entscheidenden Änderungen, die diese Fortschritte zustande gebracht haben, was Verständnis, Diagnose und Behandlung dieser Erkrankungen anbelangt. Anwendung dieser Methoden macht es möglich, eine frühe Diagnose zu stellen, was wiederum eine frühe und aggressive Therapie ermöglicht. Solch eine Haltung hat zu einer signifikanten Verbesserung des Verlaufs gegenüber der gegenwärtig immer noch praktizierten Haltung erbracht. Ähnlichkeiten und Differenzen werden analysiert. 


\section{Introduction}

The appraisal of choroiditis has been hampered in the past because imaging access to the choroid was very limited, relying mainly on B echography that gave solely gross information of the choroid, needing substantial involvement to produce a positive result [1]. As a consequence, the terminology used to characterize choroidal fundus lesions was very vague and only descriptive, including the inadequate term of "white dot syndromes" finally universally used after it was first proposed in 1995 [2]. Since indocyanine green angiography (ICGA) has become available, a much more sensitive and precise method for the exploration of inflammatory choroidal involvement is at our disposal and allows us to better identify choroidal lesions, even showing small subclinical ones, not reported by other classical diagnostic methods [enhanced depth imaging-optical coherence tomography (EDI-OCT), fluorescein angiography, slit lamp examination]. ICGA also led to a better understanding of the physiopathological mechanisms of the different choroiditis entities [3,4], thanks to a schematic interpretation in posterior uveitis using a standard protocol $[5,6]$.

Based on ICGA patterns, at least two main mechanisms at the origin of most choroiditis entities were identified [3,7]:

- Choriocapillaritis, causing choriocapillaris hypoperfusion and/ or non-perfusion [8]

- Stromal choroiditis, characterized by foci or infiltration of the choroidal stroma together with vasculitis of the larger choroidal vessels $[9,10]$

By using a global approach including multimodal imaging allowing for the assessment of inflammation in all ocular compartments, we analyzed two stromal choroiditis entities, Vogt-Koyanagi-Harada disease (VKH) and birdshot retinochoroiditis (BRC). Our purpose was to point out the striking similarities and the main differences of these two diseases regarding epidemiology and genetic background, physiopathology, inflammatory mechanism, and structures involved. This could then lead to a better understanding of the evolutionary pattern and therapy response, hoping to reach optimal management guidelines for both of these entities.

\section{ICGA for Choroidal Imaging in Inflammation}

ICGA provides profound insight into the pathological processes located in the choroid because of the specific physical and optical properties of the indocyanine green (ICG) molecule [5-7]. The almost completely protein-bound ICG molecule constitutes a macromolecular complex that is approximately 200 times larger than the small fluorescein one, giving it entirely different physical properties. Unlike fluorescein, it is too large to egress from inflamed retinal vessels unless the blood-retinal breach is very severe. In contrast, at the level of the choriocapillaris that is characterized by large fenestrations, both molecules egress alike. However, while the small fluorescein molecule is quickly washed out, the large protein-bound ICG molecule remains entangled in the choroidal stroma and progressively produces a background fluores- cence. This background fluorescence can be impaired and then produces hypofluorescent areas from at least two mechanisms: (1) choriocapillaris non-perfusion or hypoperfusion such as in choriocapillaritis [8] or (2) inflammatory foci that are infiltrating the choroidal stroma impairing the natural diffusion of the ICG molecule $[9,10]$. In the former case, the hypofluorescent areas usually have a confluent geographic aspect, whereas in the latter, the hypofluorescent dots are usually small, regular, round, evenly distributed lesions characteristic of stromal choroiditis that have been assimilated by an analogy to icebergs, otherwise unseen in the choroid [7]. The other crucial property of ICG is that it fluoresces at $830 \mathrm{~nm}$, allowing an in-depth view through the retinal pigment epithelium (RPE) of the mechanisms indicated here above. Giving access to this highly vascularized tissue, the use of ICGA in the investigation of ocular inflammatory disorders of the posterior segment appears unavoidable, enhancing the diagnostic possibilities and optimizing the management of these entities [11-14].

\section{Stromal Choroiditis}

The second ICGA pattern identified in the previous paragraph, representing inflammatory foci located in the choroidal stroma, could be referred to as stromal choroiditis [4]. The stromal choroid can be infiltrated, as other organs, by systemic diseases such as tuberculosis or sarcoidosis, a nonobligatory, chance location of a disease that involves organs in an unexplained and seemingly unrelated manner. From our perspective, this situation should be referred to as secondary stromal choroiditis as the choroid does not seem to be generating the inflammation per se but seems to only be an innocent bystander of a systemic process.

However, in primary stromal choroiditis such as VKH and BRC, the most frequent entities, the inflammatory foci, are generated by the choroidal structures themselves, which in turn triggers an autoimmune reaction. In both situations, inflammatory infiltration is accompanied by a choroidal vasculitis [6].

The ICGA features of primary stromal choroiditis are characterized by five ICG angiographic signs including [5]:

- Early hyperfluorescent stromal vessels

- Regular, round, more or less evenly distributed hypofluorescent dark dots (HDDs)

- Fuzziness and loss of pattern of large choroidal vessels in the intermediate phase

- Late diffuse hyperfluorescence

- Disc hyperfluorescence, if the inflammation is severe

A proposed angiographic scoring system allows to precisely quantify ICCA lesions with a numerical score $[15,16]$.

\section{Vogt-Koyanagi-Harada Disease (VKH)}

\section{Introduction and history}

VKH disease is a bilateral primary stromal choroiditis caused by an autoimmune reaction against a stromal melanocyte-associated protein. Ocular disease is associated with systemic manifestations, including inflammation of the meninges [cerebrospinal 
fluid (CSF)mononuclear pleocytosis], auditory disturbances, and integumentary changes (vitiligo, alopecia, and poliosis) [17].

Ocular inflammation starts in the choroidal stroma and then spills over to produce the classical clinical picture of a bilateral panuveitis with papillitis, exudative retinal detachments, and an anterior mostly granulomatous uveitis. Treatment consists of high-dose systemic corticosteroid therapy that should probably be associated with nonsteroidal immunosuppressive therapy in most cases. The first case of VKH was described in 1906 by Alfred Vogt in Switzerland who reported a case of poliosis associated with intraocular inflammation [18]. The first Japanese case of VKH disease was described by Jujiro Komoto in 1911, followed by several cases reported by Yoshizo Koyanagi in 1914 [19,20]. In 1926, Einosuke Harada described a primary posterior uveitis associated with exudative retinal detachments accompanied by CFS pleocytosis [21, 22]. In 1929, Koyanagi published his review of 16 patients with bilateral chronic iridocyclitis associated with vitiligo, alopecia, poliosis, deafness, and tinnitus [23]. In 1939, Babel, and in 1949, Bruno and McPherson unified the disorders described by Vogt, Koyanagi, and Harada, and suggested that these seemingly disparate entities were a continuum of the same disease process $[24,25]$. Since then, the uveomeningoencephalitic syndrome has been known as VKH disease.

\section{Etiology and epidemiology}

VKH eye disease is a primary stromal choroiditis caused by a multisystem TH2 autoimmune reaction against a tyrosinase-like protein in melanocytes [26-28]. VKH disease affects predominantly heavily pigmented races such as Asians, Hispanics, American Indians, and Asian Indians [17]. It can occur in Caucasians, but this is uncommon $[29,30]$. The incidence of VKH disease is variable around the world. It is more common in Japan, where it accounts for $6.8-9.2 \%$ of all uveitis referrals [31,32], than in the United States or Northern Europe, where it accounts for only $1-3 \%$ of all uveitis referrals [30].

\section{Diagnosis}

Diagnosis of typical initial-onset acute disease does not pose a problem, as characteristic symptoms and signs are those of a panuveitis, usually granulomatous, including exudative serous retinal detachments, papillitis, some vitritis, and granulomatous or nongranulomatous anterior uveitis that is progressively becoming more prominent with weeks of evolution [33]. Diagnosis is more difficult when it is not performed at the very onset of disease and when patients received suboptimal treatment before being seen by a specialized center. Therefore, several sets of diagnostic criteria have been published, starting in 1978, with those published by Sugiura [34], followed by the American Uveitis Society criteria in 1980 [35]. In 2001, the "revised criteria for VKH" were published that divided $\mathrm{VKH}$ cases into three categories, complete, incomplete, and possible VKH, which became widely used since then [36]. However, such attempts were unsatisfactory as they mixed acute and chronic features and failed to distinguish between them [37]. Today the main impact is placed on early diagnosis, which is possible thanks to ICGA and EDI-OCT choroidal thickness measurements, both positive at a rate of $100 \%$ in initial-onset disease and representing disease-defining criteria [38]. These two modalities are also essential to diagnose ongoing $\mathrm{VKH}$ in early chronic evolution.

\section{Clinical features and stages}

Prodromal stage

At the start of the disease, patients may complain of headaches (a precious diagnostic element very often present), nausea, fever, meningismus, and orbital pain. Sometimes patients complain of flu-like symptoms, scalp and skin tenderness as well as cochlearvestibular signs (tinnitus, hearing loss, vertigo) $[39,40]$. This prodromal stage usually lasts for a few days. At this stage, no ocular clinical signs are recorded yet, as the inflammatory reaction is still confined to the choroidal stroma and would be visible only by ICGA ( $\triangleright$ Fig. 1). During the prodromal stage, if symptoms are very accentuated, patients may be seen in the neurology department, in which case an MRI is usually performed and often negative [41].

\section{Uveitic acute exudative stage (initial-onset disease)}

\section{Ocular findings}

The disease becomes clinically apparent when choroidal inflammation spills over, usually very rapidly to the neighboring structures, the optic disc, retina, ciliary body, and, after a few days, the anterior chamber. By definition, the disease is bilateral, but it can be asymmetric and one eye can be involved subclinically at onset. The expression of the disease is that of a bilateral granulomatous posterior or panuveitis with predominant posterior involvement initially [42]. The symptoms consist of blurry vision and ocular discomfort. Classical anterior clinical signs are an anterior often granulomatous uveitis with minimal to moderate anterior chamber flare and cells associated with small to mid-sized granulomatous keratic precipitates (KPs) ( $\mathbf{F i g . 2}$ ). Sometimes, the degree of intraocular inflammation in acute disease is such that there is subciliary fluid accumulation at the origin of ciliary detachment causing myopisation and shallowing of the anterior chamber (• Fig. 3 ).

In initial-onset acute disease, the most severe involvement occurs posteriorly and later involves more anterior structures.

Posterior signs, early on in the acute phase of the disease, consist of swelling of the optic disc seen in conjunction with vitreous cellular infiltration of diverse amplitude. Characteristics of VKH are the multifocal exudative non-rhegmatogenous serous retinal detachments around the optic disc and in the posterior pole ( $\vee$ Fig. 2). In case the disease progresses in the absence of treatment, the serous retinal detachments can evolve into bullous retinal detachments and can involve more peripheral areas. Sometimes, in the periphery, round yellow-white lesions can be seen (Dahlen-Fuchs lesions). Retinal vasculitis is not a fundus feature of $\mathrm{VKH}[10]$.

\section{Extraocular involvement in initial-onset acute disease}

As the autoimmune reaction is also directed against melanocytes found in other parts of the body, systemic disease accompanies ocular involvement. In the acute inaugural disease, extraocular involvement predominantly involves the meninges at the origin of CSF monocytic pleocytosis, a very helpful diagnostic investigation that can be performed to confirm the diagnosis. Another extraocular site involved in acute disease is the inner ear, causing dysa- 


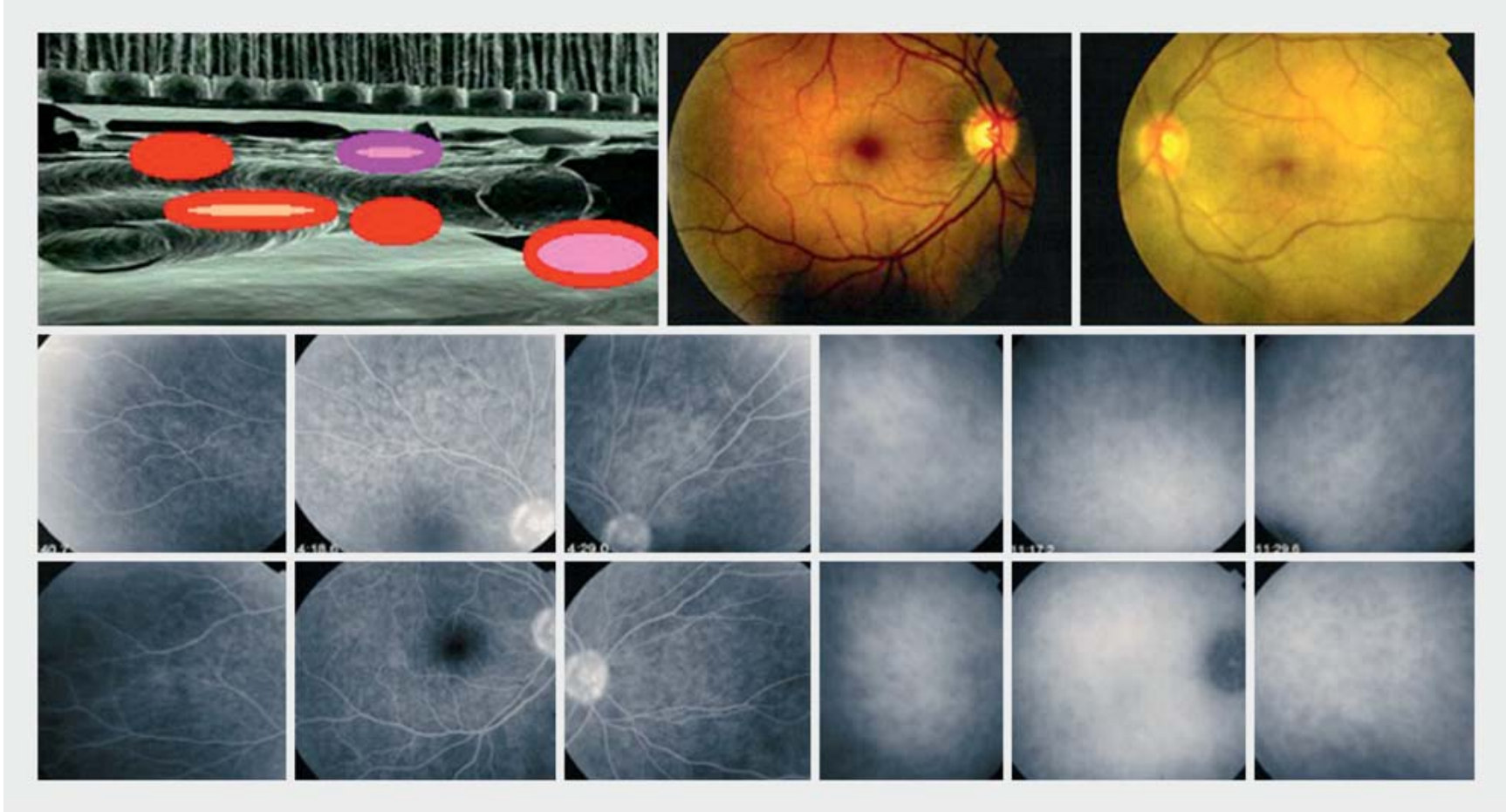

- Fig. 1 During the prodromal stage of the disease, subclinical choroidal inflammation is silently developing in the choroidal stroma, as shown in the cartoon (top left). This subclinical choroidal involvement can only be detected by ICGA. On the fundus pictures shown on the top right, the fundus of the left eye is discolored yellow due to massive choroidal VKH infiltration. The fundus of the right eye looks normal, and this patient was diagnosed as "unilateral" VKH. FA of the right eye shows no lesions (six bottom left frames), but ICGA (six bottom right frames) clearly shows numerous HDDs, indicating choroidal granuloma. (Source: Herbort CP jr., Abu El Asrar AM, Yamamoto JH et al. Reappraisal of the management of Vogt-Koyanagi-Harada disease: sunset glow fundus is no more a fatality. Int Ophthalmol 2017; 37: 1383-1395; License CC-BY 4.0)

cousis/tinnitus and hearing loss, revealed by performing an audiogram [43].

\section{Evolution to chronic disease can be stopped by early, vigorous, and prolonged therapy}

If inflammation suppressive therapy (IST) comprising steroidal and nonsteroidal immunosuppression is introduced within 3-4 weeks of onset of the symptoms, or the "therapeutic window of opportunity" [37], the disease can be cured as long as subclinical recurrences are immediately managed with increased IST. If treatment is suboptimal, the disease will evolve into the chronic stage, which is characterized by two types of courses: chronic smouldering progressing disease or chronic disease with acute exacerbations.

\section{Chronic stages of disease}

\section{Chronic smouldering progressive disease \\ Ocular findings}

In most cases, acute VKH patients receive sufficient treatment to suppress the clinically apparent disease, meaning extrachoroidal spillover disease (retina, optic disc, vitreous body). However, subclinical intraocular inflammation can persist and be detected by laser flare photometry, which can show a subclinical flare undetectable by slit lamp examination [44], or ICGA, showing active choroidal inflammation.
This subclinical evolution is at the origin of the development of "sunset glow fundus" (SGF) despite (suboptimal) therapy. SGF is explained by the progressive loss of stromal melanocytes due to low-grade choroidal inflammation. As the disease process begins to wane, the posterior portion of the globe characteristically shows depigmentation $[45,46]$ ( Fig. 4). This "sunset glow" appearance of the fundus, reflecting the stromal pigment loss, has been described to reach close to $100 \%$ in most studies and is said to be more common in Asian patients, most likely just because these fundi are more heavily pigmented.

\section{Extraocular findings}

The acute auditory difficulties can persist and may affect $30 \sim 40 \%$ of patients. They are then characterized by sensorineural hearing loss, usually involving the higher frequencies. Skin lesions (vitiligo, poliosis, and alopecia) typically occur during the chronic stage. These signs have landmarked the disease as they are very demonstrative in historical series that represent the natural course of the disease in the pretreatment era [23]. Their occurrence has decreased since more sustained therapy has been introduced [47].

\section{Chronic disease with recurrences}

Recurrences of inflammatory attacks can occur in suboptimally treated patients and/or during the tapering of therapy. These re- 

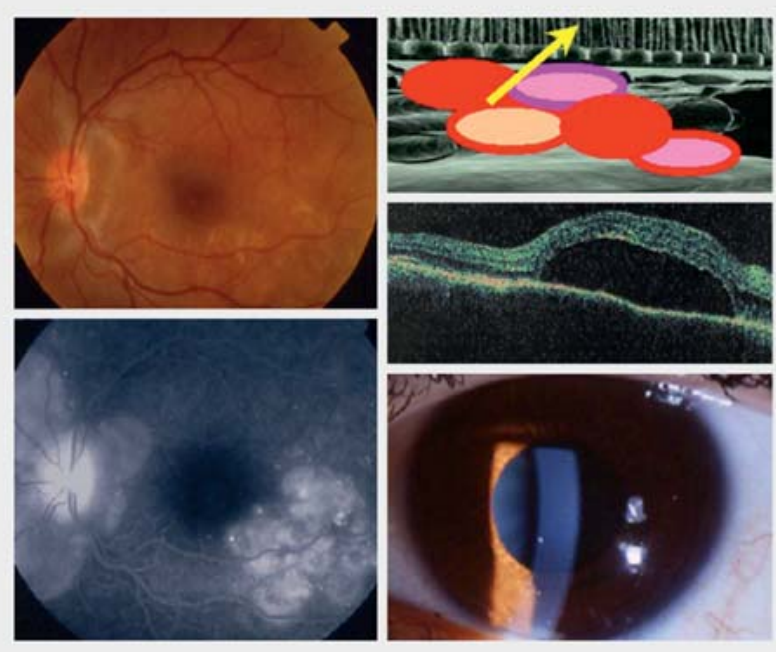

- Fig. 2 Acute initial-onset exudative VKH disease. Peripapillary and retinal exudative serous detachments seen on fuduscopy (top left) and FA (bottom left). Extrachoroidal structures are involved when the choroidal disease spills over to neighboring structures (cartoon, top right). OCT clearly shows the detachment of the neurosensory retina (middle figure on the right). Moderate granulomatous anterior uveitis accompanying posterior involvement (bottom right). (Source: Herbort CP jr., Abu El Asrar AM, Yamamoto JH et al. Reappraisal of the management of Vogt-Koyanagi-Harada disease: sunset glow fundus is no more a fatality. Int Ophthalmol 2017; 37 : 1383-1395; License CC-BY 4.0)

current attacks resemble the uveitic acute exudative stage, with some differences. Their characteristics will depend on how important the stromal choroidal melanocytes loss was during the initial uveitic acute stage and the subsequent smouldering phase of disease. If the loss of melanocytes was important, the predominant part of the inflammation will be anterior, as it is classically described, because this is probably where the bulk of the remaining melanocytes is. However, if the loss of choroidal stromal melanocytes was scarce, recurrences can present themselves similar to de novo uveitic acute exudative disease. Nevertheless, the posterior component of inflammation is usually less pronounced and, although serous exudative detachments can occur, this is a much rarer feature. Anterior granulomatous uveitis is a more prominent feature, with its classical signs of granulomatous KPs that can take a mutton-fat aspect and that are very often pigmented, together with Koeppe nodules, diffuse iris infiltration or Bussacca nodules, and irido-crystalline synechiae ( $\mathbf{F i g}$. 4). Sometimes, what seems to be a purely anterior recurrence is associated with a subclinical posterior recurrence only shown by the resurgence of HDDs on ICGA [48].

\section{Complications}

SGF seems to be the consequence of smouldering choroiditis in insufficiently treated disease and can be avoided if early, adequately dosed, and prolonged therapy is given to suppress clinical and/or occult choroidal inflammation [47]. It should therefore be considered a complication of undertreated cases. As in all poste-

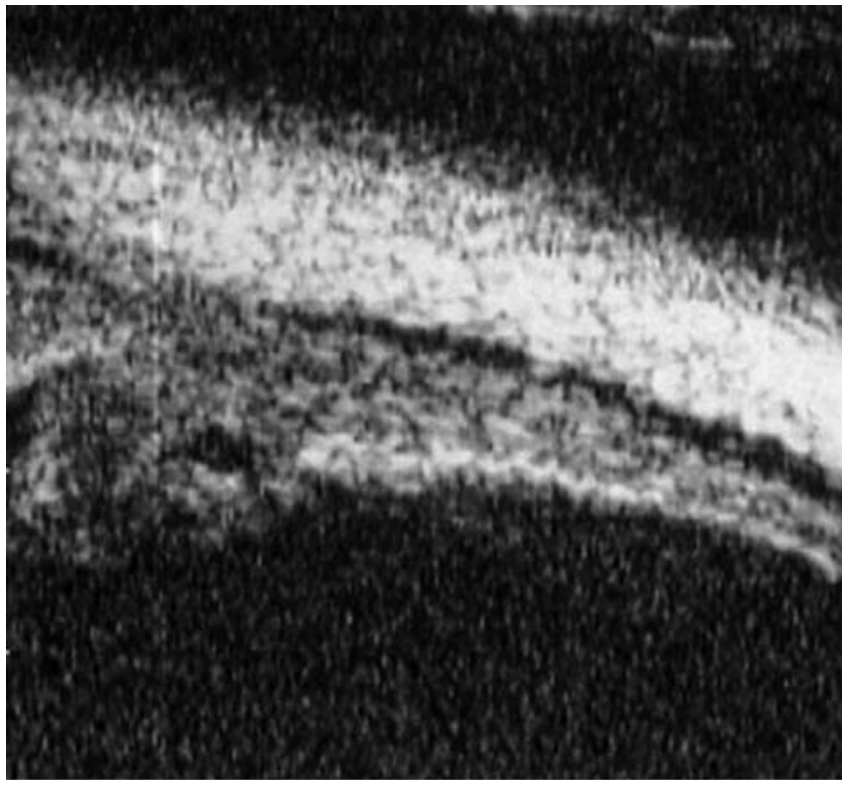

- Fig. 3 Subciliary detachment in hyperacute VKH disease. Ultrasound biometry (UBM) picture showing liquid under the ciliary body producing ciliary body detachment that caused acute myopisation.

rior inflammatory diseases, choroidal neovascularization (CNV) may occur. The proportion of patients with CNV is difficult to establish and varies among series, but appears to be occurring in less than $5 \%$ of cases. With the availability of intravitreal anti-VEGF agents, the prognosis of inflammatory CNVs has become much better [49].

Glaucoma, occurring in up to $27 \%$ of VKH patients, should be managed along the usual guidelines of inflammatory glaucoma [50]. Cataracts, usually cortico-induced, occur in up to $42 \%$ of VKH patients. All these numbers reflect an era with suboptimal treatment, and should be treated with caution.

\section{Investigational procedures}

\section{Fluorescein angiography (FA)}

In the uveitic acute exudative stage of the disease, FA characteristically shows numerous punctuate hyperfluorescent pinpoint dots at the level of the RPE [51] ( $\vee$ Fig. 2). These dots gradually become more fluorescent, as dye is progressively leaking into the subretinal space and stains the surrounding subretinal fluid. The homogeneous pooling of the fluid clearly outlines the full extent of neurosensory detachments. Optic nerve hyperfluorescence is classically seen. In the subacute and chronic stages, when the exudative retinal detachments have resolved, FA generally demonstrates areas of fluorescence transmission (window defect) and blockage in the areas of damaged, clumped RPE ( $\bullet$ Fig. 4). At this stage, the characteristic high water line can be seen, identifying the limits the detachments reached, and is represented by the abrupt transition from the granular rearranged area of the pigment epithelium to the uniform screen of intact RPE ( $\triangleright$ Fig. 4). At this stage, there is also very often a persistent disc hyperfluorescence, indicating ongoing disease that is nearly always confirmed by the presence of choroidal lesions seen on ICGA 

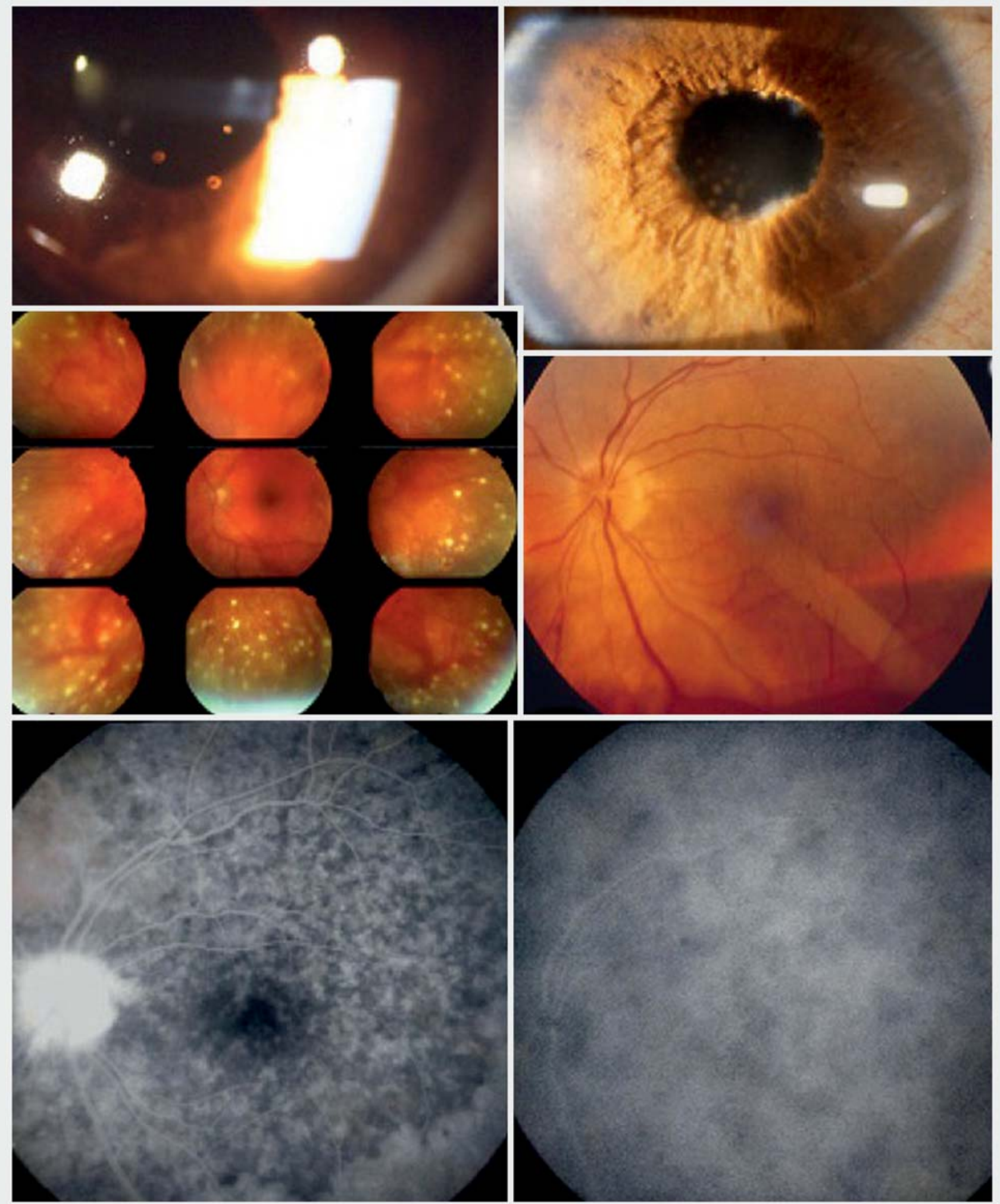

- Fig. 4 Signs found in chronically evolving disease. Chronic granulomatous uveitis with old pigmented KPs (top left), Koeppe nodules, iris infiltration, and Bussacca nodules (top right). Scars from Dalen-Fuchs nodules are shown on the middle left picture and sunset glow fundus on the right middle picture. Mottled irregular, disturbed RPE in the posterior pole and high water marks indicate a limit of reattached serous retinal detachment as well as disc hyperfluorescence, as seen on the FA frame (bottom left). Only ICGA can show that the disease is still active, as shown by the numerous dark dots (bottom right). (Source: Herbort CP jr., Abu El Asrar AM, Yamamoto JH et al. Reappraisal of the management of Vogt-KoyanagiHarada disease: sunset glow fundus is no more a fatality. Int Ophthalmol 2017; 37: 1383-1395; License CC-BY 4.0) 
( $\vee$ Fig.4). FA beautifully outlines the extra-choroidal lesions of uveitic acute exudative disease, but most of the time does not add essential information that is not already available by clinical examination and fundus photography. The retina itself is not involved primarily in $\mathrm{VKH}$, but lesions are secondary to choroidal inflammation.

\section{Indocyanine green angiography ( $\bullet$ Fig. 5)}

Being a primary stromal choroiditis, the initial inflammatory events in VKH start in the choroidal stroma before massively infiltrating the full thickness of the stroma, and ICGA is therefore the method of choice to establish and monitor choroidal inflammation $[52,53]$. In that respect, ICGA is able to detect early subclinical disease as well as subclinical recurrences during tapering of IST, which OCT in its EDI mode is not able to do [54].

Many publications on ICGA signs in VKH are available $[55,56]$. However, these publications include VKH cases at different stages and no clear definition of ICGA signs before therapeutic intervention has been given. Information from ICGA publications was difficult to interpret. Herbort et al. systematized the ICG findings trying to identify signs that are consistently found and useful for the follow-up of choroidal involvement [57]. They identified four signs, the most important being HDDs indicating stromal granulomas ( $\triangleright$ Fig. 5). The three other reliable ICGA signs for evaluation and follow-up were early hyperfluorescent choroidal vessels, fuzzy indistinct large choroidal vessels indicating choroidal vasculitis and ICGA disc hyperfluorescence ( $\bullet$ Fig. 5 ). Other ICGA signs seen are inhomogeneity of choriocapillaris perfusion and late diffuse choroidal hyperfluorescence, which are, however, difficult to evaluate in a standard fashion. A recent study showed that these ICGA signs were also present in Japanese as well as Saudi Arabian patients, indicating that they are universally found signs $[58,59]$.

The ICGA signs were seen in quasi $100 \%$ of the fresh, de novo, untreated disease, and the first sign to respond to therapy was disc hyperfluorescence. In acute recurrent attacks, the same signs can be observed. However, in chronic smoldering disease, only HDDs and fuzzy indistinct choroidal vessels indicate ongoing choroidal inflammation.

Precise measurement of retinochoroidal inflammatory involvement is available thanks to a proposed angiographic scoring system $[15,16]$.

ICGA was also able to show, in our cases, with seemingly unilateral disease, that there was in fact occult choroiditis in the controlateral eye ( $\triangleright$ Fig. 1). Therefore, there is probably no such thing as unilateral VKH, as in all published cases of alleged unilateral VKH, ICGA had not been performed to exclude subclinical controlateral choroiditis before starting treatment.

\section{Optical coherence tomography (OCT) and enhanced depth imaging (EDI)}

OCT has been shown to be a useful tool to measure and monitor serous retinal detachments during the acute and chronic stages of VKH disease, with the ability to show shallow serous detachments not otherwise seen [60]. However, OCT is mainly better at showing extrachoroidal spillover retinal involvement and does not give information on subclinical smouldering choroidal disease.
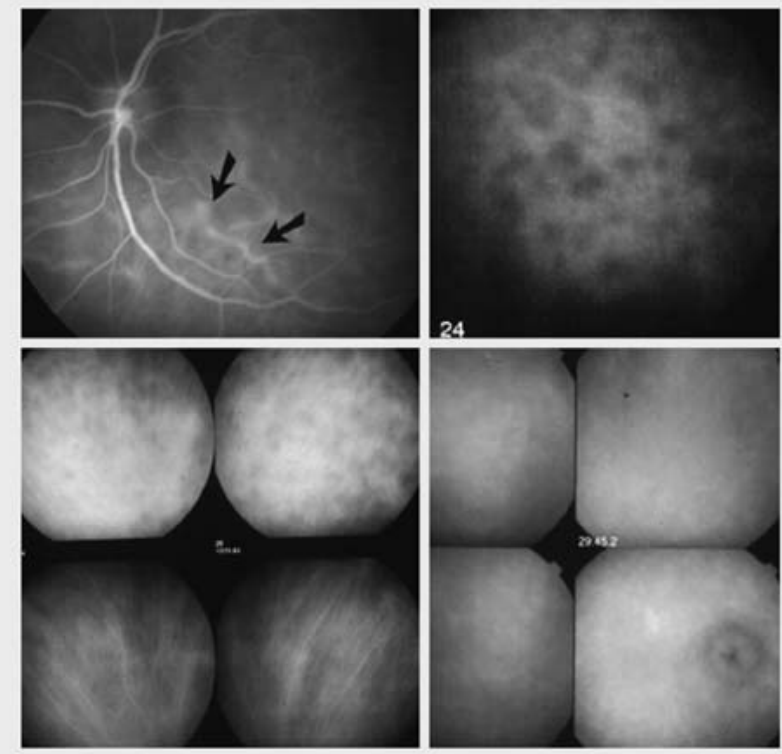

- Fig. 5 ICG angiographic signs. ICGA is the only technique to analyze choroidal inflammatory signs, including early stromal hyperfluorescent vessels (top left), HDDs, indicating choroidal granuloma (top right), and fuzzy indistinct choroidal vessels (top two frames of bottom left quartet). After 3 days of intravenous megadoses of methylprednisolone, the normal pattern of vessels is again recognizable (bottom two frames of bottom left quartet). Bottom right quartet of frames shows diffuse late hyperfluorescence and a hyperfluorescent inflamed disc. (Source: Herbort CP jr., Abu El Asrar AM, Yamamoto JH et al. Reappraisal of the management of VogtKoyanagi-Harada disease: sunset glow fundus is no more a fatality. Int Ophthalmol 2017; 37: 1383-1395; License CC-BY 4.0)

Since the introduction of EDI-OCT, various studies reported the importance of monitoring choroidal involvement by measuring its thickness, another useful modality that will help to lead to a rapid diagnosis of initial-onset disease [61]. EDI-OCT is also useful to follow the long-term evolution of choroidal thickness [62]. It is, however, not useful, due to not being reactive enough, to monitor the evolution of choroidal inflammation in the acute and postacute phases. Moreover, it does not give information on the peripheral choroid [54].

\section{Other investigational procedures}

Ultrasound biometry (UBM) is not an essential investigation for VKH but, in the uveitic acute exudative stage when acute myopisation is occurring, UBM will show subciliary exudation [33] ( $\bullet$ Fig. 3). For a long time, classical B-scan ultrasound (US) analysis was the only device that could give information on choroidal involvement until ICGA and EDI-OCT became available, but is now obsolete. CSF analysis shows mononuclear pleocytosis in most patients at the same time or soon after the onset of ocular symptoms and may persist much longer than is usually reported. Therefore, CSF testing by performing a lumbar puncture is best when done early in the disease for confirmation of the diagnosis [63]. In atypical cases, or in cases modified by previous (insufficient) treatment, CSF analysis is still justified several months after 
onset, as in our hands it is far from unusual to get positive results. Autorefraction can show refractive changes due to massive subciliary choroidal effusion, producing myopic changes, and can be used for monitoring purposes [33]. Laser flare photometry is very useful in $\mathrm{VKH}$, as it can exactly determine the degree of anterior chamber inflammation. In a recent study [10], the mean flare value for VKH at presentation was $119.5 \pm 179.5 \mathrm{ph} / \mathrm{ms}$ (range 3.7 to 629 , $n$ of eyes $=12$ ).

\section{Treatment}

The principal problems in the treatment of VKH patients are twofold.

1. The deferral in the initiation of therapy because of diagnostic delay [64], especially in non-endemic areas.

2. The presently practiced therapy that is aimed at the suppression of the clinically apparent disease and that is adjusted and tapered only according to the resolution of the extrachoroidal, clinically visible disease.

The treatment regimen published and practiced for VKH from our perspective seems to be insufficient regarding the immunosuppression used as well as the dosage and duration. When the clinically apparent disease is controlled under initial therapy with normalization of functional and morphological parameters such as visual acuity, fundus picture, retinal OCT, and FA, monitoring by ICGA has shown that choroidal inflammation is still active and progressing [65]. This persistence of choroidal subclinical disease is explaining the evolution towards SGF in most case series receiving standard therapy $[45,46]$.

Therefore, in our opinion, VKH therapy has two phases. First, treatment of the uveitic acute exudative and post-acute stages of the disease, and monitoring of the resolution of choroidal inflammation with the help of ICGA in the convalescent phase. Second, ICGA-assisted adjustment and discontinuation of therapy with a reincrease of therapy with each subclinical ICGA detected recurrence of choroidal inflammation as well as ICGA monitoring of choroidal inflammation once therapy has been discontinued [53, 54].

\section{Acute uveitic exudative stage and post-acute stage} (2 months)

The severity of VKH disease and its propensity to respond to treatment can be very diverse. In recent years, it has become increasingly clear that dual steroidal and nonsteroidal immunosuppressive IST is recommended, although a proportion of mild cases might be overtreated [64]. A 3-day course of intravenous methylprednisolone (500 to $1000 \mathrm{mg}$ per day) is recommended followed by high-dose oral prednisone (1.0 to $1.2 \mathrm{mg} / \mathrm{kg}$ ) for 4-6 weeks. At the onset of disease, we tend to combine systemic prednisone with ciclosporine (CsA), a quick acting immunosuppressant and mycophenolic acid, which becomes effective only after several weeks with progressive tapering of corticosteroids over a period of 4-6 months, progressive tapering CsA over a period of 6-9 months, and long-term maintenance of non-steroidal immunosuppressive therapy such as mycophenolic acid. When persisting or recurring subclinical choroidal inflammation is detected by ICGA, an additional immunomodulator such as an anti-TNF- $\alpha$ agent is added [66].
Determination of efficacy of a therapeutical agent is greatly helped by ICGA, as it is reactive and a response is seen quickly when the chosen therapy is efficient. ICGA gives the clinician great security to monitor tapering. In case of recurrence of subclinical ICGA-detected choroiditis (reappearance of HDDs), IST is reincreased and/or a novel immunomodulatory substance is added $[53,54,67]$.

Long-term tapering of inflammation suppressive therapy until absence of recurrence of choroidal disease

Tapering off with treatment takes much longer than the treatment duration that is usually recommended, until successful tapering without subclinical disease recurrence in the choroid is achieved. In a series of 9 patients treated with ICGA-assisted management, the mean duration of treatment was 27.3 months \pm 38.2 months (range 9-114), which is much longer than the 6 to 9 months cited in the literature. The advantage of such a relentless therapy is a high proportion (7/9 cases, 78\%) of "healed" cases with no recurrent activity within a mean follow-up period without therapy of $26 \pm 14.8$ months as well as a low proportion of cases with sunset glow fundus (3/9, 33\%) [53].

\section{Treatment of chronic VKH disease}

In case the disease has escaped to chronicity because of insufficient or late treatment, the objective can no longer be curing the disease. In most cases, the disease will evolve in a smouldering fashion with acute recurrences sometimes, mostly clinically anterior associated with subclincal stromal choroiditis identified by ICGA. Therapy will have less impact, and more than one immunosuppressant is usually necessary. The choice of therapy is often made by trial and error. ICGA monitoring is often helpful as the effectiveness of a given therapy can be verified by the response of ICGA signs (HDDs and choroidal vasculitis, angiographic score). The response to therapy will also advantageously be followed with laser flare photometry.

\section{Birdshot Retinochoroiditis (BRC)}

\section{Introduction and history}

BRC is a bilateral retinochoroidal inflammatory disease without any known systemic involvement described in 1980 by Ryan and Maumenee [68]. A report by Gass in 1981 described 11 patients with the same condition that he originally called vitiliginous chorioretinitis [69]. Association of BRC with major histopathology complex (MHC) type 1 antigen HLA-A29 was reported in 1982 and confirmed in 1992, as being one of the strongest associations known to date $[70,71]$. The particular clinical characteristic of BRC is that inflammation starts dually and independently in the choroid and the retina, unlike most uveitis entities where inflammation originates in one structure involving secondarily adjacent structures [72,73]. At the level of the retina, profuse leaking vasculopathy involves both small capillaries and large retinal vessels. The choroidal involvement typically is a primary stromal choroiditis, initially occult, and later producing the typical rice-shaped depigmented yellow birdshot lesions in the posterior pole and along the vascular arcades ( $\bullet$ Fig. $\mathbf{6 a}$ ). Initially, BRC was not differenti- 


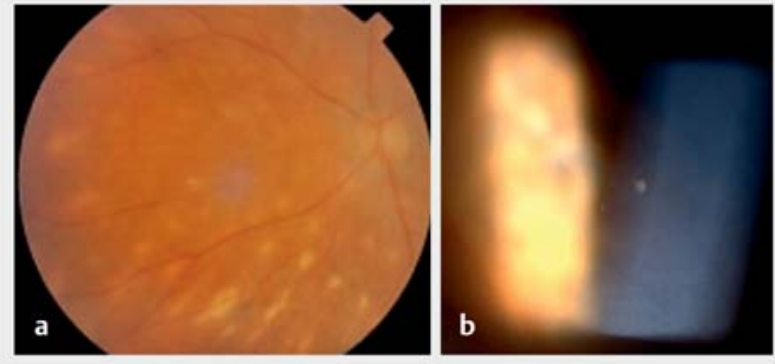

- Fig. 6 a BRC fundus appearance. Typical oval-shaped depigmented fundus lesions distributed in the mid-periphery in a patient with a disease evolving for more than 7 years. b Anterior segment view of a non-treated BRC patient showing one single microgranulomatous KP.

ated from other choriocapillaris entities such as multiple evanescent syndrome (MEWDS), and was even included in the "white dot syndromes", however, histopathology has revealed that it is the choroidal stroma that is the site of inflammation, while the choriocapillaris and the RPE are intact. This therefore differentiates BRC, and makes it rather a stromal choroiditis [2,74]. Unfortunately, it is still included in the choriocapillaritis group, albeit the physiopathlogical mechanism is different [75]. It should further be noted that it is a primary stromal choroiditis, as explained earlier, in contrast to other diseases like sarcoidosis or tuberculosis. The obligatory primary site of inflammation is the stroma in BRC [76].

In contrast to VKH disease, where the target of the immune reaction, a stromal choroidal melanine-associated protein, has been identified, the target of the suspected autoimmune reaction in $B R C$ is unknown. However, the morbidity in BRC comes from retinal inflammatory involvement due to massive leakage from capillaries and larger vessels $[77,78]$.

\section{Etiology and epidemiology}

BRC mainly affects Caucasian patients, an ethnic group with a high prevalence of the HLA-A29.2 antigen [71]. The presence of the HLA-A29 antigen increases the risk of developing the disease, up to 224-fold [79]. The proportion of BRC patients in a European and North American uveitis series is around $1.2 \%$ of uveitis cases. In Southeast Asian populations, BRC has virtually never been found or described. Typically, BRC affects age groups from 30 to 70 years with a median age around 50 and there is a strong gender predilection for women, with an $\mathrm{F} / \mathrm{M}$ ratio of $3 / 2[80,81]$.

\section{Diagnosis}

Over the years, several attempts of establishing diagnostic criteria have been made, including one to establish research criteria for the disease [82]. Although the authors initially presented them for study purposes, these criteria have often been treated as diagnostic ones and are often miscited. Crucial elements such as ICGA and visual field testing were not listed, while others had only minor attention (HLA-A29). KPs were listed as an exclusion criterion, although studies showed them to be present in as much as $20 \%$ of cases [83]. The main issue of this miscitation was, that by not including ICGA, clinicians deprive themselves of the possibility to make an early diagnosis, before typical oval, depigmented, birdshot fundus lesions are present. Recently, newer diagnostic criteria, reporting early BRC diagnosis, were published and included (1) retinal vasculitis in small and large veins in one or both eyes, (2) vitritis in one or both eyes, (3) visual field abnormalities in one or both eyes, (4) ICGA lesions in both eyes (present in 100\% of cases, required criterion), and (5) the presence of the HLA-A29 antigen (required), with or without oval, depigmented, birdshot fundus lesions [84].

\section{Clinical features}

$\mathrm{BRC}$, in contrast to $\mathrm{VKH}$, is a disease that involves immediately both the choroid and the retina in a parallel but independent fashion [73]. Involvement is always bilateral, like VKH, but can be asymmetric.

Patients may have ocular complaints such as floaters, loss of brightness and of luster of colors, fuzziness of vision and, only later, a decrease in visual acuity. As macular edema often spares the foveola, central vision remains excellent in most cases and is not a good functional parameter to monitor disease activity and progression, whereas visual field changes more appropriately identify the progression of the disease [85-87]. Anterior chamber inflammation is usually slight, at most, with a flare only recordable by laser flare photometry [88] and rare cells. Nevertheless, careful examination of the anterior segment is important. In cases with a long-standing evolution that have not been treated, it is not rare to find very few or even a single microgranulomatous KP [83] ( $\bullet$ Fig. 6b). Interestingly, BRC diagnosis criteria from 2006 exclude patients with KPs or posterior synechiae [82]. However, Knecht et al. reported granulomatous KPs in up to $23 \%$ of cases, contradicting this exclusion criteria [89]. Moreover, signs possibly indicating a granulomatous process in BRC have been found histopathologically in a recent autopsy case of BRC, and could further confirm this result, although no complete granulomas were identified [74]. Vitreous infiltration is usually present and can be prominent in some cases. At the onset of disease, fundus examination shows papillitis and vasculitis of veins, but no cream-colored birdshot fundus lesions, which used to be considered the landmark sign of BRC ( $\bullet$ Fig. 7 a, b). However, subclinical choroidal involvement is clearly shown by ICGA through numerous HDDs, indicating occult stromal choroidal infiltration [89] ( Fig. 7c,d). The initial extent of retinal involvement is shown by FA, which reveals, in addition to vasculitis of large vessels, massive capillary exudation to the point that there is not enough fluorescein upon venous return to mark the large veins [77]. This stage is called the wet phase of BRC ( $\bullet$ Fig. 7 e). In our experience, cystoid macular edema (CMO) involving the foveola is less frequent than reported in the past and occurs in up to $40 \%$ of cases at any time of the evolution of the disease. Even when there is massive exudation from retinal vessels, the foveola can remain free of edema $[76,90]$ ( $\vee$ Fig. $7 \mathbf{f}$, left eye). On the other hand, in equally inflamed eyes, one eye may present $\mathrm{CMO}$, whereas the other eye remains free of it ( $\bullet$ Fig. $\mathbf{7 f}$ ).

For ongoing disease, especially in belatedly diagnosed cases and if treatment is insufficient, the fundus examination reveals 


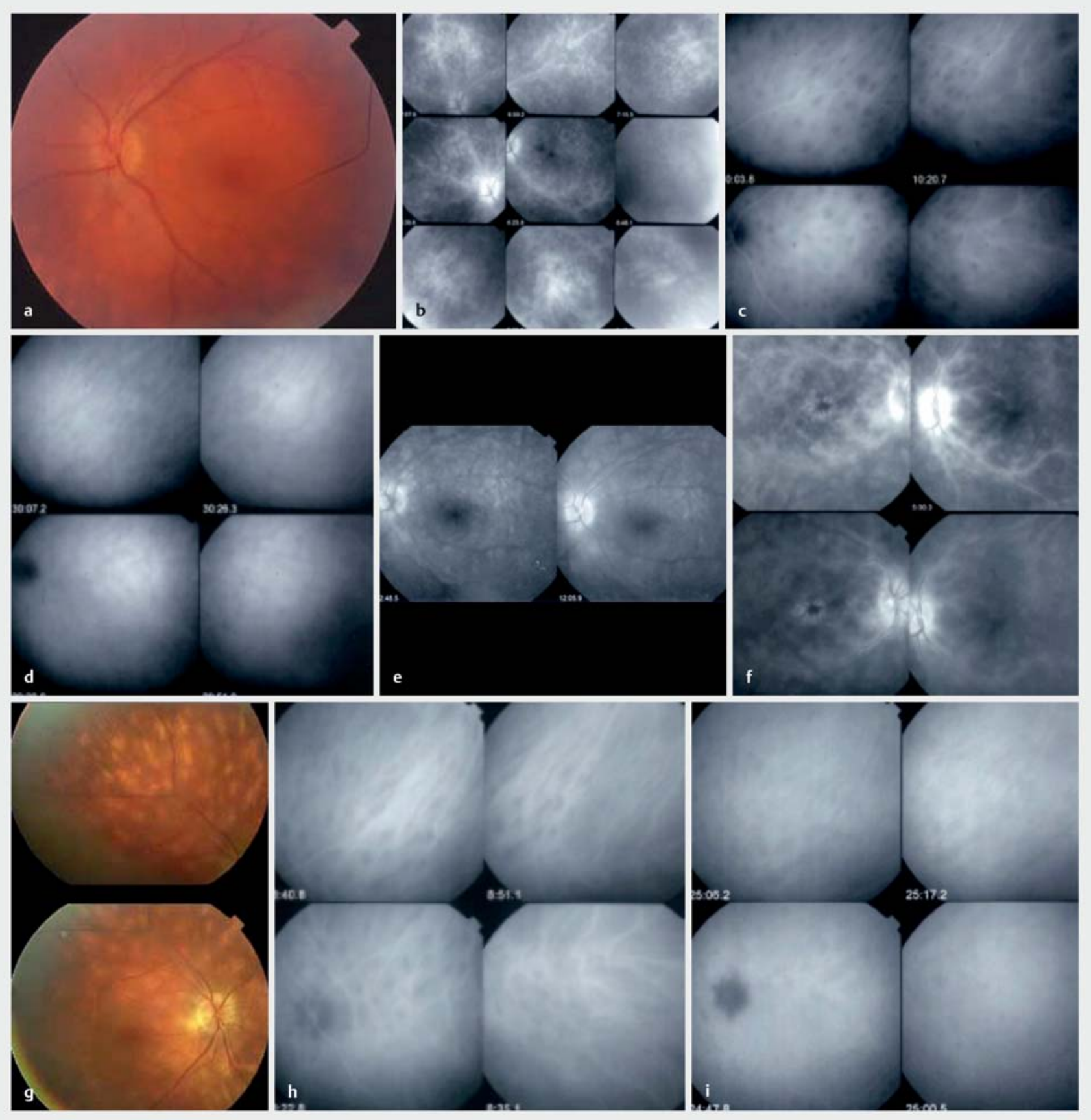

- Fig. 7 Benign case of BRC managed by close follow-up without treatment. Fifty-eight-year-old patient that consulted for fuzzy vision with floaters. At presentation the fundus examination showed minimal signs limited to a slight depigmentation of the fundus (a). FA showed disc hyperfluorescence, vasculitis of the large vessels, and patchy mottled hyperfluorescence caused by leakage of small retinal vessels (b). ICGA showed numerous HDDs in the intermediate angiographic phase. Some of these dots persist into the late phase, probably representing full-thickness choroidal inflammatory infiltrates, but most are no longer detected in the late phase as the hyperfluorescence coming from large abnormally permeable vessels causes isofluorescence ( $c$ and $\mathbf{d}$ ). Even at the presenting stage of the disease, there was a lack of fluorescein demarcation of the veins, not due to a circulatory delay, as the ICG angiographic taken at 20" already shows dye in the veins. This is explained by the massive intraretinal leakage from small retinal vessels, so that there is never enough dye in the large veins to opacify them (e). It was decided to watch the patient without treatment because visual acuity was not diminished, visual field changes were minimal, and there was no cystoid macular edema (CME) in the left eye (f). After 6 years without treatment, the visual acuity and visual fields did not deteriorate, fundus lesions increased (g), and ICGA HDDs diminished $(h, i)$ but the macula remained free of CME. 
progressively more cream-colored, oval, birdshot fundus lesions ( $\vee$ Fig. $\mathbf{7 g}$ ). Regression of ICGA dark dots occurs following therapy ( $\vee$ Fig. $\mathbf{7 h}, \mathbf{i}$ ). It is supposed that this corresponds to the resolution of the lymphocytic infiltration without stromal scarring but bearing with it the depletion of melanocytes corresponding to the cream-colored birdshot fundus lesions. Therapy usually allows stabilization of the disease, but in some cases diagnosed with delay, the process can evolve towards a pseudo-retinitis pigmentosa when extensive damage is caused to the chorioretina ( $\vee$ Fig. 8 a). The functional corollary is a badly damaged visual field, with reduced color vision in parallel with reduced amplitudes in electroretinography [91, 92] ( Fig. 8 b).

\section{Investigational procedures}

Fluorescein angiography (FA)

FA accounts for the retinal involvement and optic nerve inflammation in BRC. FA findings in the active phase of the disease need to be distinguished from FA findings in quiet or burned out disease. In early active disease, FA shows sectorial vasculitis of large vessels, mainly retinal veins. The predominant sign, however, is diffuse vasculitis of small vessels (capillaries) that is at the origin of mottled hyperfluorescence all over the fundus, termed the wet phase of BRC ( $\triangleright$ Fig. 9a). These widespread mottled areas of hyperfluorescence do not correspond to the dark hypofluorescent dots seen in ICG, clearly indicating that choroidal or retinal inflammations are not the consequence of each other, but develop independently $[73,76]$. In many cases, this massive fluorescein leakage from capillaries or precapillary arterioles is at the origin of diffuse retinal fluorescein impregnation. The leakage is often such that there is not enough fluorescein to mark the large veins [77] ( $\vee$ Fig. $\mathbf{9 b}$ and $\mathbf{7 e}$ ). This was erroneously interpreted by Gass in his article on "vitiliginous chorioretinitis" as an arteriovenous circulatory delay [69]. When dual FA and ICGA is performed, actually no arteriovenous perfusion delay is seen, as the ICG dye reaches the central vein within 20 seconds after injection into the antecubital vein ( $\bullet$ Fig. $\mathbf{9 b}$ and $\mathbf{7 e}$ ). The failure to see fluorescein in the large veins is explained by the fact that, due to massive retinal exudation, there is not enough fluorescein to sufficiently impregnate the large veins and make them fluoresce [77] ( $\bullet$ Fig. 9 b and 7e). Consequently, retinal function is impaired in cases with such a massive exudation from small and large retinal vessels.

Disc hyperfluorescence of diverse intensity is usually seen in all cases of early active disease. CMO is best investigated by FA at onset and can be followed by FA. In addition, OCT allows for a closer follow-up of CMO [78,90,93]. In our series of patients mostly under corticosteroid/Immunosuppressive treatment, the rate of patients presenting a CMO with foveolar involvement did not exceed $30-40 \%$ [72] ( $\triangleright$ Fig. 7f).

In burned-out or quiet long-lasting cases, the main FA findings are mostly window defects of atrophic areas, showing early hypofluorescence and late hyperfluorescence. Retinal vessels tend to become slender and, in some cases, chorioretinal atrophy can evolve towards a pseudo-retinitis pigmentosa fundus picture. There are very often chronic edematous macular changes or macular retinal pigment alterations as a sequel of long-standing retinal fluid impregnation.

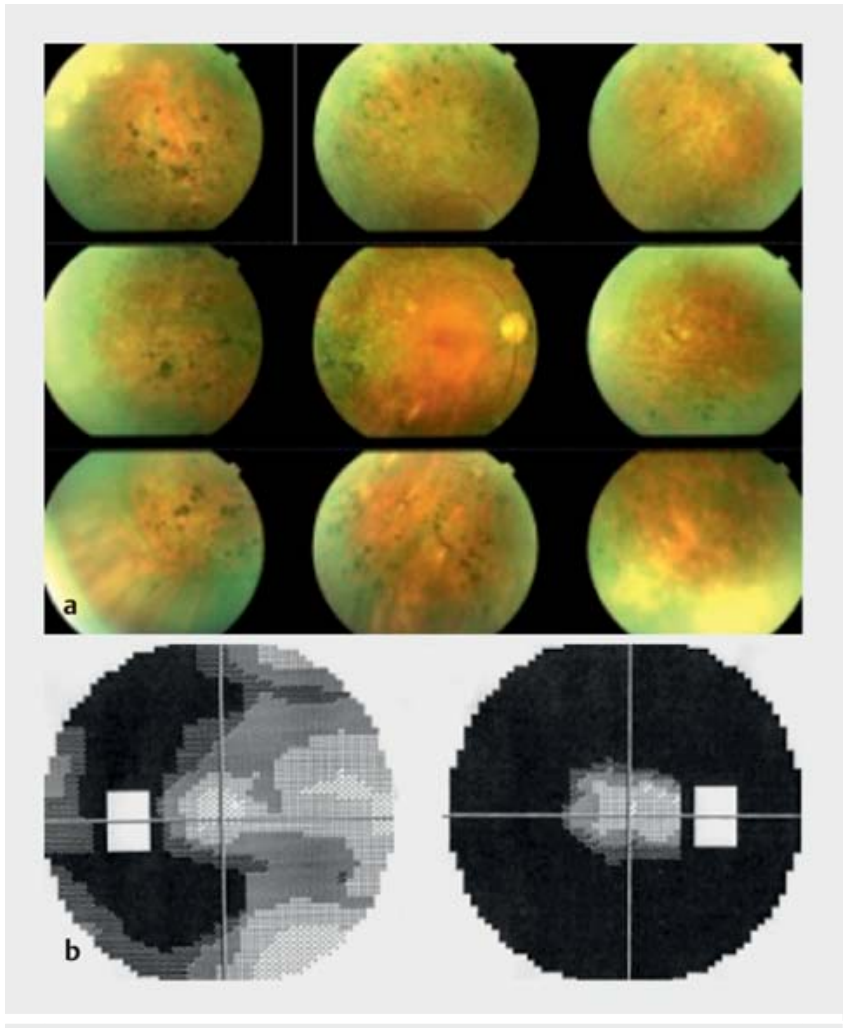

- Fig. 8 Case of burnout BRC, despite maximal therapy, with a fundus picture resembling retinitis pigmentosa fundus (a) and severely altered visual fields (b).

\section{Indocyanine green angiography (ICGA)}

So far, only the retinal involvement was accessible for clinical and angiographic examinations and could be analyzed in detail. Since ICGA has become available, choroidal inflammatory involvement became accessible to analysis and monitoring [5]. ICGA represents a major improvement in the investigation of BRC by showing the importance of choroidal involvement. The interpretations given to the characteristic ICGA images obtained from BRC patients were only conjectures that have, however, now been confirmed by histopathological analysis of an autopsy case of BRC [74].

Like FA, ICG angiographic findings have to be distinguished according to the stage and activity of the disease. For diagnostic purposes, ICGA is most useful in a newly presenting disease, as it detects subclinical choroidal stromal infiltration prior to the apparition of fundus signs [93]. Later, ICGA is a great tool to monitor the choroidal inflammatory evolution during therapy.

In early and non-treated disease, the main findings are numerous HDDs that correspond to stromal inflammatory foci shown by histopathology ( $\vee$ Fig. 7 c, d, 10 a-e, 11 a, b). They have a regular size and are evenly distributed in the posterior pole and the midperiphery, and have the value of a disease-defining criterion, as they are present in $100 \%$ of cases at a time when the characteristic oval shaped, cream-colored, birdshot fundus lesions are not yet present. The case exposed in $\mathbf{F i g . 1 0}$ a-e shows that in the early stage of disease, fundus lesions are not yet visible, whereas ICGA clearly shows a birdshot type of involvement of the choroid 

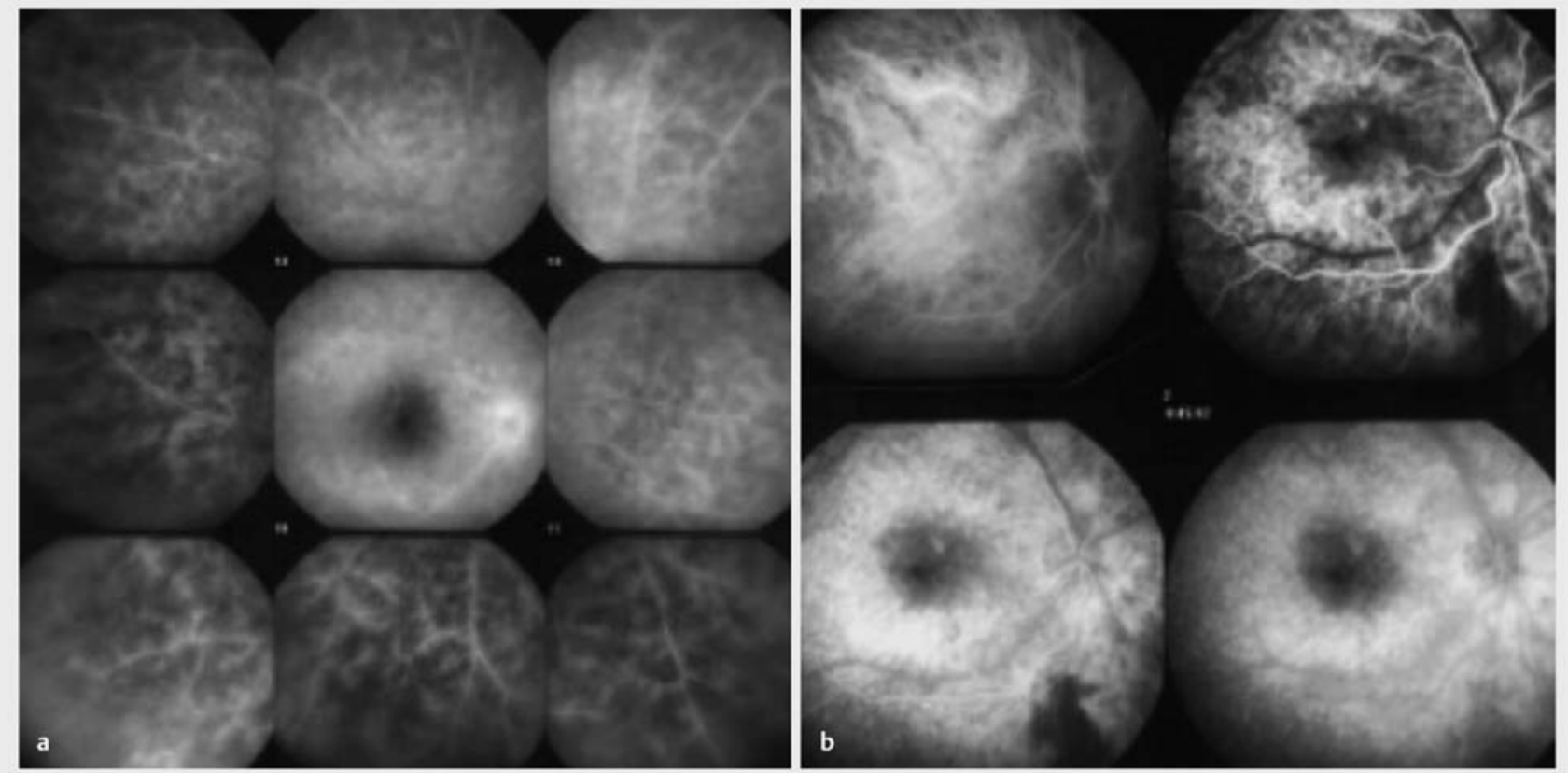

- Fig. 9 a Leakage of the microvasculature. FA shows diffuse, patchy, mottled hyperfluorescent areas all over the fundus, indicating diffuse vasculitis of the small vessels. b Pseudo-delay in retinal arteriovenous circulation. Massive retinal exudation causing a pseudo-delay of arteriovenous circulation as large veins are still not opacified at 45 seconds.

( $\triangleright$ Fig. 10a-e). These HDDs are detected from the post-early angiographic frames, but are best seen during the intermediate and/or late phase of angiography ( $\mathbf{F i g . 7} \mathbf{c}$ and $\mathbf{9}$ a). They either persist up to the late angiographic phase or become isofluorescent in the late phase depending on whether the foci occupy the whole thickness of the stroma or are only partial thickness granulomas ( $\bullet$ Fig. 7 c, d and $\mathbf{1 1}$ a,b). Typically, the physiopathological process explaining the HDDs in BRC is the principle proper to ICGA of a "mass effect", where a space occupying an inflammatory lesion in the choroidal stroma impairs the normal diffusion of the ICG dye physiologically extruding from the fenestrated choriocapillaris ( $\vee$ Fig. 12). In addition to visualization of the infiltrates, ICGA also shows vasculitis of the larger choroidal vessels that have a fuzzy appearance in the intermediate phase of angiography and give rise to late diffuse choroidal hyperfluorescence [93] ( $\triangleright$ Fig. 13a,b). The hypothesis of a vasculitic process at the origin of the fuzzy appearance seen on ICGA has also been confirmed by histopathology since the first ICGA reports [74]. This abnormal leakage from large choroidal vessels also contributes to "erase" the partial thickness stromal foci in the late phase of ICGA ( $\vee$ Fig. 14). It has to be stressed that these findings consisting of HDDs and fuzzy vessels are not pathognomonic to BRC, but can also be found in other diseases such as VKH disease, where the same physiopathological processes of stromal infiltrates and choroidal vasculitis are present.

The ICGA findings in treated or quiet disease are less pronounced and reflect the good response of choroidal lesions to corticosteroid/immunosuppressive therapy. HDDs tend to resolve, and the larger choroidal vessels regain a normal aspect with pro- gressive resolution of their fuzzy aspect. The remaining HDDs have a less regular shape and correspond to chorioretinal atrophy.

Objective and precise measurement of retinochoroidal inflammatory involvement can be evaluated thanks to a previously published angiographic scoring system [16, 94].

\section{Optical coherence tomography (OCT) and enhanced depth imaging-OCT (EDI-OCT)}

1. OCT is an extremely useful modality to analyze and follow-up retinal morphology and has shown retrospectively in a collective of suboptimally treated patients that the retina goes through different phases from early presentation were it is thickened and exudative, through an intermediate phase were retinal thickness decreases, to a late phase, where we find a thinned atrophic retina with a very high rate of epiretinal membranes (ERM) [78].

2. EDI-OCT has been increasingly used recently and is showing choroidal thickening in initial-onset disease, a characteristic feature of BRC, contributory for diagnosis. In suboptimally treated patients, choroidal thickness progressively thins over years. This evolution can be significantly attenuated when patients are treated early and in a prolonged fashion [95].

\section{Visual field testing}

We have shown that apart from central visual impairment due to macular edema, visual field changes are more frequently found than acknowledged in BRC and have probably more deleterious effects on visual function than recognized so far $[85,86]$. These visual field changes are probably a consequence of retinal dysfunc- 

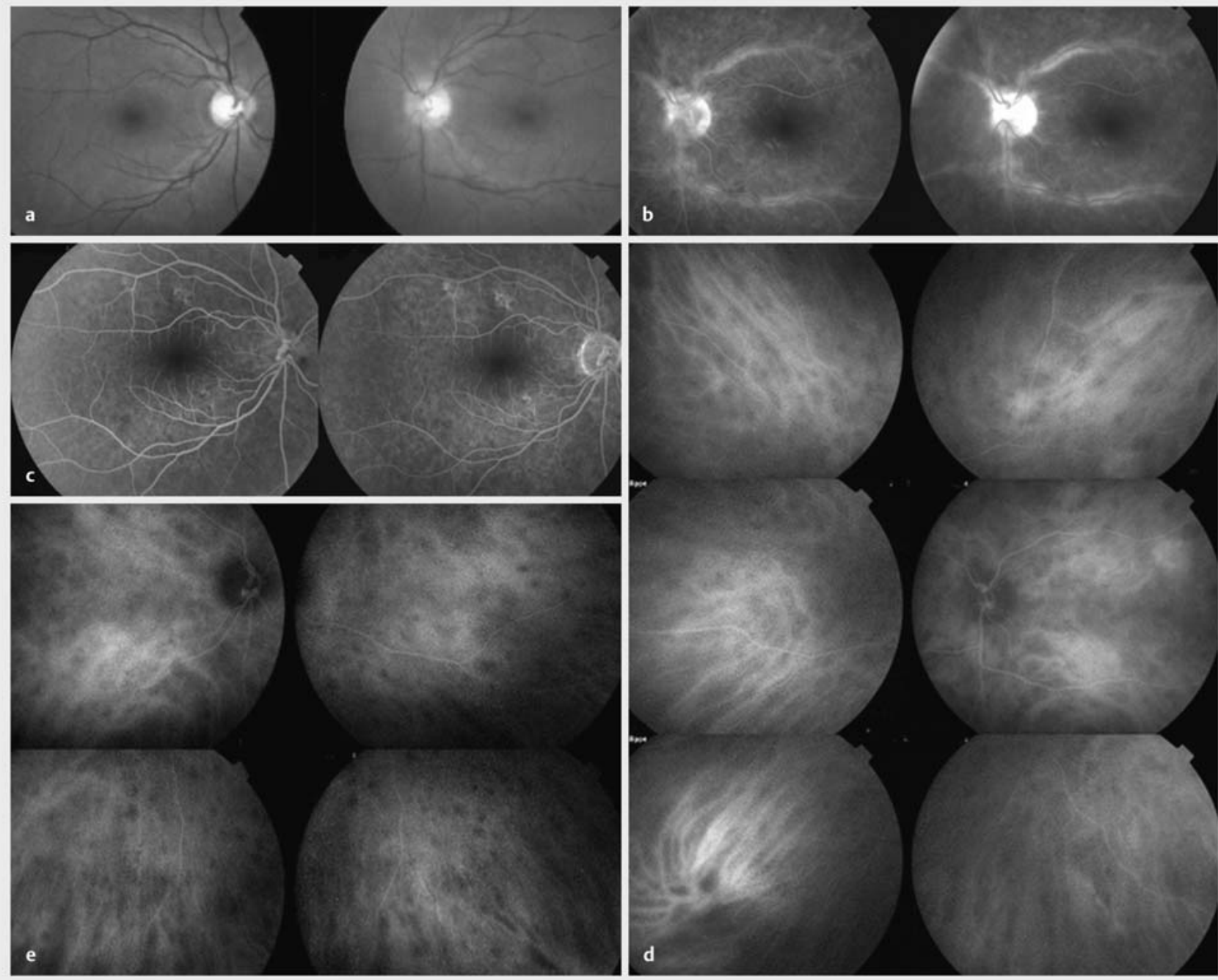

- Fig. $10 \mathrm{BRC}$ in the early stage of disease. Forty-two-year-old man who consulted for blurred vision OS. Diffuse vitritis without fundus lesions in the left eye (a); FA shows pronounced retinal vasculitis in the symptomatic left eye (b) and minimal changes in the asymptomatic right eye (c); ICGA clearly shows numerous HDDs in the left symptomatic eye (d) but even more HDDs in the right asymptomatic eye (e). Based on the left fluorescein signs and bilateral ICGA signs, BRC was suspected, and the search for the presence of the HLA-A29 antigen was performed, which tested positive.

tion rather than from choroidal or optic nerve disease and are seen in parallel to massive fluorescein exudation [87] ( $\vee$ Fig. 11 c, d). In our hands, since our first data on the importance of visual field testing, computerized visual field testing is a routine follow-up examination and the occurrence or progression of visual field changes are considered an indication to introduce or increase therapy, despite full visual acuity. This attitude may be an explanation why the rate of foveolar cystoid macular edema is relatively low in our experience [72].

\section{Electroretinography and physiopathological implications}

Full-field electroretinogram (ERG) becomes abnormal as the disease progresses, indicating relentless retinal deterioration. The ERG can show a decrease of the rod a- and b-wave amplitudes with an increase of their implicit times [87], but the most sensitive and prevalent abnormality is a delay of the cone system-derived
$30 \mathrm{~Hz}$ flicker ERG [91]. Priem et al. showed that the neural layers of the retina were more diffusely and severely involved than the receptor-RPE-choroid complex with the observation of an electronegative ERG. There is little evidence indicating outer retinal dysfunction resulting from choroidal inflammation [92].

These findings are in contrast to ERG findings reported in primary inflammatory choriocapillaritis where outer retinal dysfunction is found and therefore distinguishes BRC from choriocapillaritis entities also electrophysiologically and they should not be classified together [3].

\section{Optical coherence tomography angiography (OCTA)}

Recent reports [96-98] have started to describe OCTA findings in $B R C$ and have found a diffuse reduction in the flow of both the superficial (SCP) and the deep capillary plexus (DCP), with capillary loops, telangiectatic vessels, and overall signs of altered reti- 

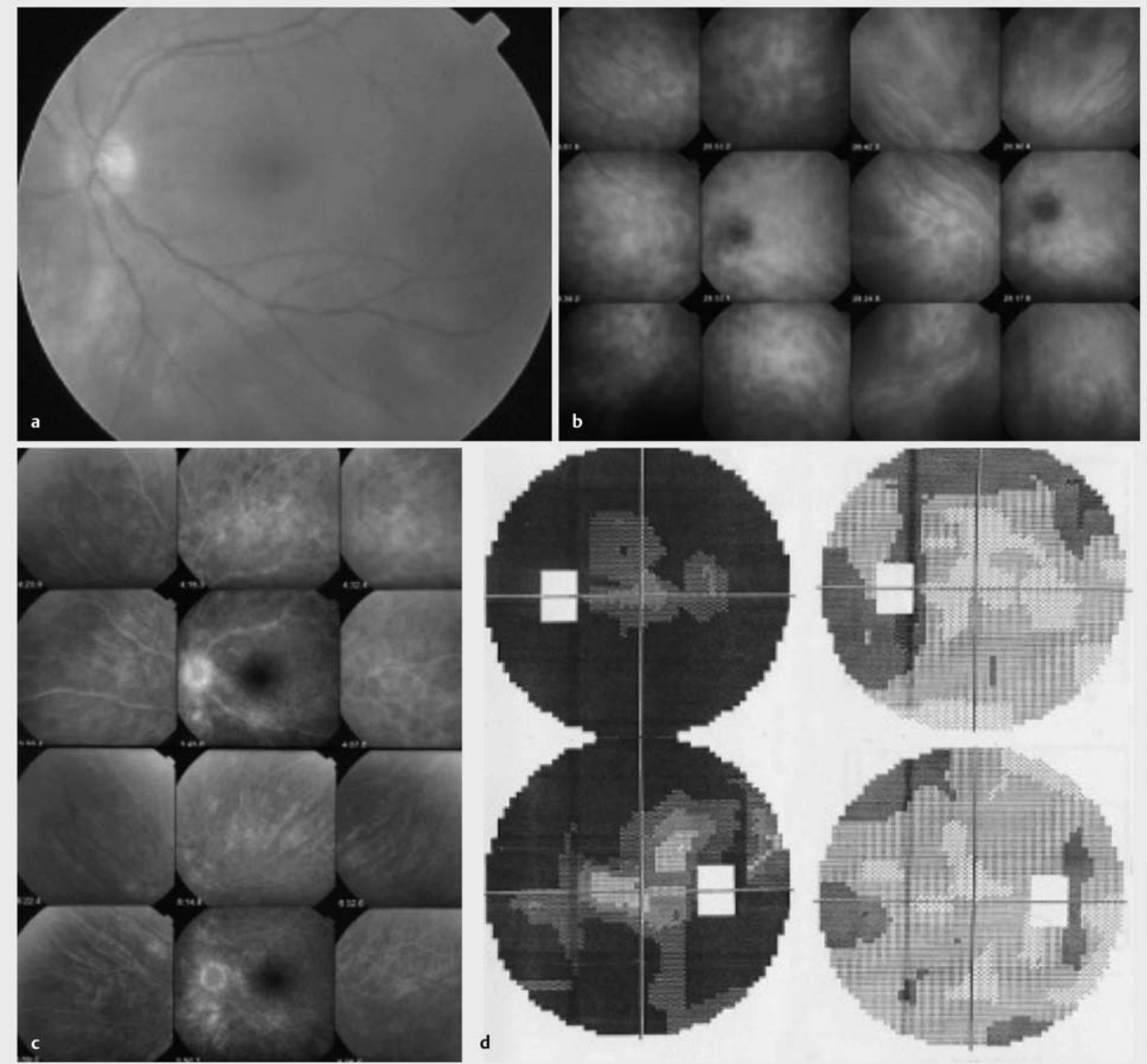

- Fig. 11 BRC with severe functional impairment at presentation. Fifty-seven-year-old woman that presented with floaters and an impression of dimness of vision. Fundus imaging shows minimal signs with only faint dyspigmentation (a). Typical oval-shaped hypofluorescent dots seen in early disease, while fundus lesions are still discrete and scarce. These lesions responded very well to emergency posterior sub-Tenon's steroid injection (b, set of six pictures on the right). Presence of severe large and small retinal vessel vasculitis (c, six top frames) that also responded well to subTenon's steroid injection (c, six bottom frames). The presenting visual fields showed extremely severe changes that, to a large extent, regressed after initiation of therapy (d).

nal vasculature. Changes were more noticeable in the DCP than in the SCP.

\section{Evolution, prognosis, and treatment}

Evolution and prognosis of BRC is traditionally considered to cause long-term visual impairment due to several complications such as cystoid macular edema, scarring, or choroidal neovascular membranes. Studies reported up to $20 \%$ of patients having long-term best-corrected visual acuity of $20 / 200$ or less $[99,100]$. However, publications have often hinted that adequate control of intraocular inflammation, and subsequent disease remissions, would permit significant visual improvement, or even restoration [101, 102]. Such an attempt is even more possible thanks to substantially improved diagnostic means, allowing early diagnosis prior to the apparition of cream-colored birdshot fundus lesions. Recent studies have shown that aggressive early treatment in patients could prevent the apparition of the typical birdshot lesions, 

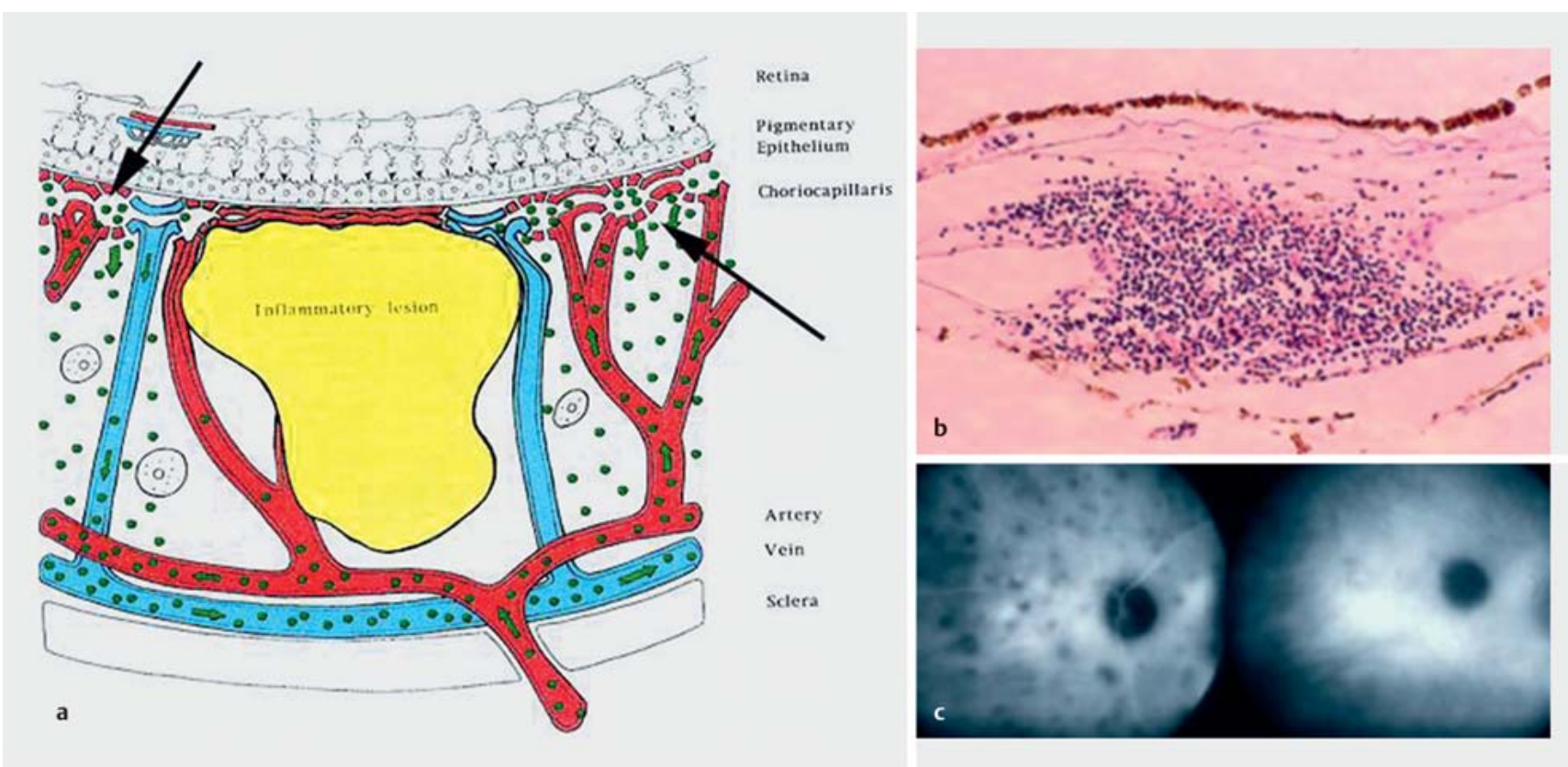

- Fig. 12 HDDs in BRC. (a) Cartoon explaining the "mass effect" of a granuloma partially occupying the choroidal stroma. (b) Recent histopathology seems to confirm this hypothesis, clearly showing a partial thickness choroidal infiltrate (courtesy Drs. Gaudio, Brooks-Crafword, and Rao). Exudation from inflamed large choroidal vessels explains both the late diffuse hyperfluorescence and the fact the partial thickness lesions are "erased" in the late angiographic phase (c). (Source for $>$ Fig. 12 a: Bruno Jeannin)

even after a follow-up of more than 10 years [85], and even prevent thinning and atrophy of the choroid [95].

As discussed earlier, BRC is characterized by a primary dual simultaneous, although independent, involvement of the retina and the choroid. The evolution and response to therapy of retinal and choroidal disease in BRC have a different course, with choroidal disease responding well to therapy while retinal disease is more resistant.

As prospective control studies are lacking due to the rarity of the disease, management of BRC is empirical. BRC can be left untreated only as long as no functional impairment is detected, however, early management of intraocular inflammation should be rapid. In the absence of cystoid macular edema, the first functional parameter to deteriorate is not visual acuity but the visual field. If this deterioration is progressing, action should be taken promptly. Several treatment options have been tried in this regard, but none have been consensual. Steroids, regardless of their route, are usually part of the initial regimen and have been proven to improve edema, neovascular membranes, and even symptoms of nyctalopia [103-105], however, most agree that the effect is limited in late-stage disease. Immunosuppressive agents have also been commonly used, but take longer to be efficient and the results are similar, with a combined approach usually favored over a corticosteroid only or immunosuppressive only management $[102,106]$.

One safe and efficient approach could be to start with subTenon's corticosteroid injections, which could be repeated in case of asymmetrical disease, either accompanied by a fast-acting immunosuppressant such as CsA, or a slower but safer one such as mycophenolic acid or even anti-TNF agents. Fifteen percent of the patients reported did not need systemic therapy after 10 years of follow-up.

There is no set treatment protocol for BRC and the choice of therapy is often empirical. Traditionally, disease recurrence and evolution are evaluated by EDI-OCT measured choroidal thickness, or FA, however, such methods do not detect small subclinical recurrences as efficiently and quickly as ICGA. ICGA is a powerful tool to determine whether a given therapy has an impact on the disease in a given patient, as the ICGA scoring system is effective and promptly able to show whether the disease is improving or not following the introduction of a new therapy. After initial IST with corticosteroids, the efficient treatment can be fine-tuned through ICGA monitoring, or more precisely, HDDs $[54,67]$.

In case of efficient therapy, the ICGA HDDs respond well to therapy and resolve, leaving behind depigmented areas that appear as oval, cream-colored, birdshot fundus lesions unless treatment has been started early, which avoids the development of such lesions. In contrast, the impact of therapy on retinal involvement is less satisfactory, explaining the progression of functional loss despite therapy. in some cases. with a deleterious course.

In recent years, additional knowledge has been gained and significant progress has been made in the understanding and management of BRC. Clinical signs such as micro-granulomatous KPs, although rare and not well known, indicate that BRC is to be classified as a granulomatous uveitis. The importance of ICGA to make the diagnosis early in the disease when there are no fundus lesions present yet, and its use to follow choroidal involvement and determine efficacious therapy, has been demonstrated and the presence of ICGA lesions has become a disease-defining criterion [84]. Some publications, having assimilated HDDs to birdshot fun- 


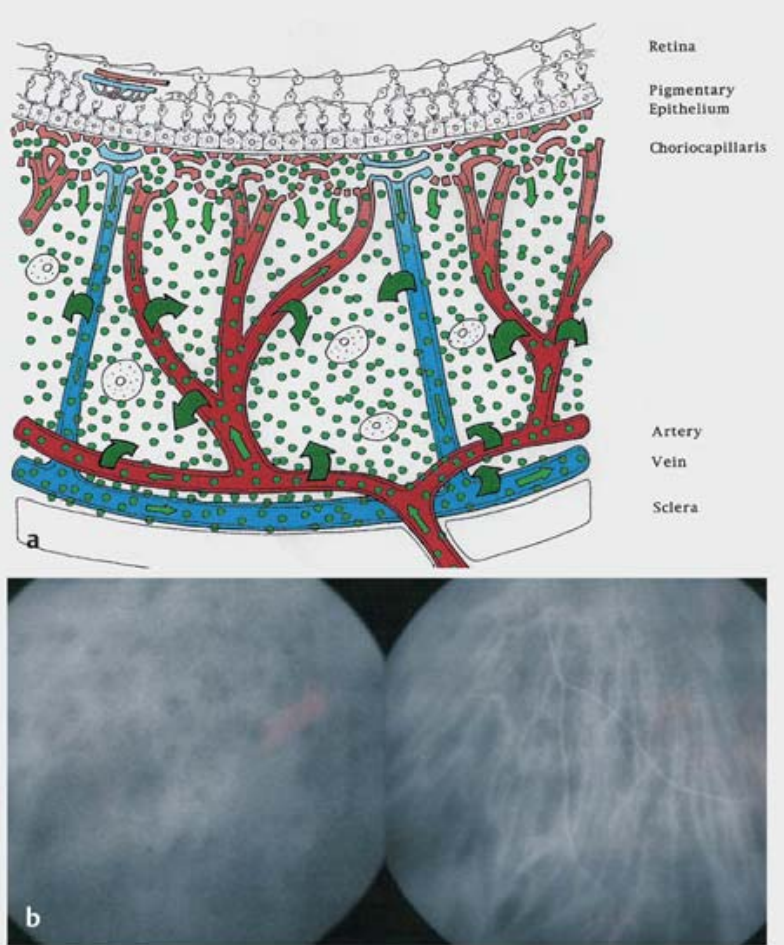

- Fig. 13 Fuzziness of large choroidal vessels. (a) Cartoon explaining the pathological choroidal hyperfluorescence in addition to the physiological background fluorescence from the choriocapillaris, coming from non-fenestrated large vessels. Inflamed vessels appear fuzzy in the area with numerous HDDs (b, left), rapidly responding to corticosteroid therapy with their pattern more sharply visible again (b, right). (Source for $>$ Fig. 13a: Bruno Jeannin)

dus lesions, have created some confusion. Cream-colored, oval, birdshot fundus lesions represent scars (atrophy) of ex-foci having left behind depigmented areas. In contrast, HDDs are active foci and do not correspond to birdshot fundus lesions [107] ( $\bullet$ Fig. 14). Hence, identification of HDDs by ICGA can be used and has been used to determine the degree of activity of BRC [108]. Finally, the importance of visual field testing in the therapeutic decision process and for the follow-up of the disease has only recently been recognized at large and should be the principal functional parameter to follow, as visual acuity often remains very good despite disease progression.

\section{Similarities and Differences between VKH and BRC and Consequences of the Therapeutic Approach}

VKH and BRC are both primary stromal choroiditis entities with inflammatory events starting and occurring primarily in the choroidal stroma. If the basic mechanisms are the same, choroidal involvement differs between the two on several points. In VKH, the inflammatory process is more severe and foci occupy the whole

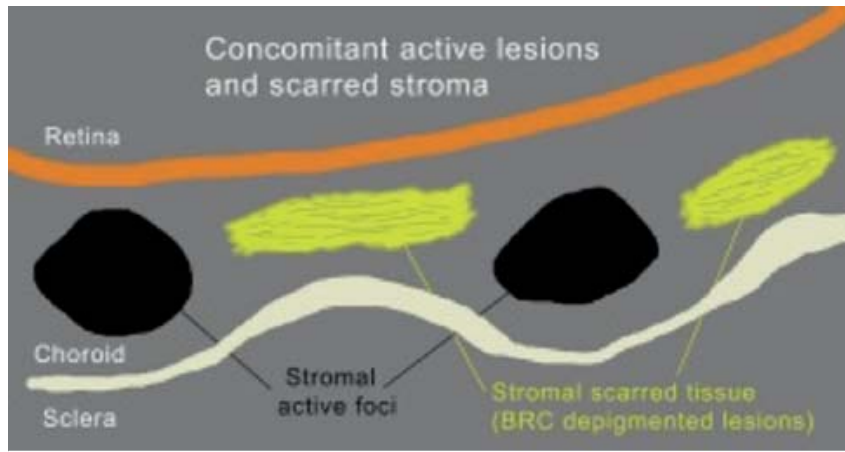

- Fig. 14 Cartoon showing the difference between depigmented birdshot fundus lesions and ICGA HDDs (Source: Bruno Jeannin).

- Table 1 Differences and similarities of Vogt-Koyanagi-Harada disease $(\mathrm{VKH})$ and birdshot chorioretinopathy (BRC), a summary.

\begin{tabular}{|l|l|l|}
\hline Similarities & VKH & BRC \\
\hline Stromal choroiditis & ++++ & +++ \\
\hline Depigmentation type & Sunset glow fundus & $\begin{array}{l}\text { Birdshot fundus } \\
\text { lesions }\end{array}$ \\
\hline HLA association & + & $\begin{array}{l}++++ \\
100 \%(H L A-A 29)\end{array}$ \\
\hline Response to Tx (Choroid) & $\begin{array}{l}\text { (DR4, DRB1 }{ }^{*} \text { 0405) } \\
++++ \\
\text { (if high dose IST) }\end{array}$ & +++ \\
\hline Response to Tx (Retina) & N/A & ++ \\
\hline Granulomatous uveitis & +++ & + \\
\hline Differences & VKH & BRC \\
\hline Ethnicity & $\begin{array}{l}\text { Asians/Orientals/His- } \\
\text { panics/Amerindians }\end{array}$ & Caucasians \\
\hline Primary disease location & $\begin{array}{l}\text { Choroid exclusively and } \\
\text { secondary involvement } \\
\text { of adjacent structures }\end{array}$ & $\begin{array}{l}\text { Choroid and } \\
\text { retina }\end{array}$ \\
\hline Acute or hyperacute & $\begin{array}{l}\text { Chronic, indolent } \\
\text { persistent }\end{array}$ \\
\hline Disease intensity & $\begin{array}{l}\text { Excellent, cure possible } \\
\text { if aggressive treatment }\end{array}$ & $\begin{array}{l}\text { Good, but } \\
\text { chronic evolution }\end{array}$ \\
\hline Prognosis & &
\end{tabular}

choroidal thickness, producing, in cases of insufficient treatment, widespread areas of depigmentation called sunset glow fundus. On the other hand, in BRC, the process is more discreet and foci are smaller and usually non-coalescent. They do not touch the RPE internally and don't extent as far as the sclera externally, producing the typical oval, cream-colored, birdshot fundus lesions when inflammation subsides. ICGA signs are similar, showing the same choroidal vasculitis (fuzzy vessels) and an identical pattern of HDDs. Because lesions are of partial thickness in BRC, HDDs may become isofluorescent in late ICGA frames. Because of the more explosive inflammation in $\mathrm{VKH}$, severe cases can show ICGA disc hyperfluorescence, which is never the case for BRC.

The major difference between the two entities is, however, the fact that in VKH, only the choroid generates inflammation that is secondarily, affecting adjacent structures such as the retina and 
optic disc. In BRC, inflammation comes concomitantly from the choroid and the retina. This explains why treatment is more successful in VKH, because once choroidal inflammation is under control, the rest of the inflammation subsides. In BRC, choroidal inflammation responds in the same positive fashion as $\mathrm{VKH}$, whereas retinal inflammation is more difficult to control as it is an autonomous process and not only the consequence of choroidal inflammation. This also explains why maximal therapy can cure VKH, whereas BRC is irremediable, having a chronic evolution with treatment that cannot be stopped in most cases. Therefore, treatment has to be introduced within 3-4 weeks for VKH if a cure is the objective, whereas treatment should be introduced for BRC in the first months of disease onset in order to best control inflammation, for lack of being able to eradicate it. - Table 1 shows a summary of the differences and similarities of these two diseases ( $\bullet$ Table 1).

\section{Conclusions}

The appraisal of both VKH and BRC has been marked by substantial progress in the past years. Diagnostic and monitoring modalities have become extremely effective, allowing for early diagnosis, which, in turn, led to the emergence of the concept that initial-onset disease has to be treated as early as possible, which is especially crucial for VKH. Application of these principles resulted in a cure of the disease for VKH and avoidance of the development of sunset glow fundus, and a change in the phenotype for BRC, devoid of the classical oval, cream-colored, birdshot fundus lesions.

\section{Conflict of Interest}

The authors declare that they have no conflict of interest.

References

[1] Forster D], Cano MR, Green RL et al. Echographic features of the VogtKoyanagi-Harada syndrome. Arch Ophthalmol 1990; 108: 1421-1426

[2] Ben Ezra D, Forrester JV. Fundal white dots: the spectrum of a similar pathological process. Br J Ophthalmol 1995; 79: 856-860

[3] Herbort C. Choroiditis: general considerations and classification. In: Pleyer U, Mondino B, eds. Essentials in Ophthalmology: Uveitis and immunological Disorders. Berlin, Heidelberg, New York: Springer; 2004: 202-208

[4] Bouchenaki N, Herbort CO. Stromal choroiditis. In: Pleyer U, Mondino B, eds. Essentials in Ophthalmology: Uveitis and Immunological Disorders. Berlin Heidelberg, New York: Springer; 2004: 234-253

[5] Herbort CP, LeHoang P, Guex-Crosier Y. Schematic interpretation of indocyanine green angiography in posterior uveitis using a standard angiographic protocol. Ophthalmology 1998; 105: 432-440

[6] Bouchenaki N, Cimino L, Auer C et al. Assessment and classification of choroidal vasculitis in posterior uveitis using indocyanine green angiography. Klin Monatsbl Augenheilkd 2002; 219: 243-249

[7] Herbort CP, Papadia M, Mantovani A. Classification of choroiditis based on inflammatory lesion process rather than fundus appearance: enhanced comprehension through the ICGA concepts of the iceberg and jellyfish effects. Klin Monatsbl Augenheilkd 2012; 229: 306-313
[8] Cimino L, Auer C, Herbort CP. Sensitivity of indocyanine green angiography for the follow-up of active inflammatory choriocapillaropathies. Ocul Immunol Inflamm 2000; 8: 275-283

[9] Gillmann K, El Ameen A, Massy R et al. Assessment of measurement methods of posterior inflammation in stromal choroiditis: the value of quantitative outcome measures versus the presently qualitatively based paradigm. Int Ophthalmol 2018. doi:10.1007/s10792-018-0979-y

[10] Fabro F, Herbort CP. Need for Quantitative Measurement Methods for Posterior Uveitis: Comparison of Dual FA/ICGA Angiography, EDI-OCT Choroidal Thickness and SUN Vitreous Haze Evaluation in Stromal Choroiditis. Klin Monatsbl Augenheilkd 2018; 235: 424-435

[11] Herbort CP. Posterior uveitis: new insights provided by indocyanine green angiography. Eye (Lond) 1998; 12: 757-759

[12] Herbort CP, Mantovani A, Papadia M. Use of indocyanine green angiography in uveitis. Int Ophthalmol Clin 2012; 52: 13-31

[13] Herbort CP, Neri P, El Asrar AA et al. Is ICGA still relevant in inflammatory eye disorders? Why this question has to be dealt with separately from other eye conditions. Retina 2012; 32: 1701-1703

[14] Yannuzzi LA. Indocyanine green angiography: a perspective on use in the clinical setting. Am J Ophthalmol 2011; 151: 745-751.e1

[15] Tugal-Tutkun I, Herbort CP, Khairallah M; Angiography Scoring for Uveitis Working Group. Scoring of dual fluorescein and ICG inflammatory angiographic signs for the grading of posterior segment inflammation (dual fluorescein and ICG angiographic scoring system for uveitis). Int Ophthalmol 2010; 30: 539-552

[16] Tugal-Tutkun I, Herbort CP, Khairallah M et al. Interobserver agreement in scoring of dual fluorescein and ICG inflammatory angiographic signs for the grading of posterior segment inflammation. Ocul Immunol Inflamm 2010; 18: 385-389

[17] Lavezzo MM, Sakata VM, Morita C et al. Vogt-Koyanagi-Harada disease: review of a rare autoimmune disease targeting antigens of melanocytes. Orphanet J Rare Dis 2016; 11: 29

[18] Vogt A. Frühzeitiges ergrauen der Zilien und Bermerkungen über den sogenannten plötzlichen Eintritt dieser Veränderung. Klin Monatsbl Augenheilkd 1906; 44: 228-242

[19] Herbort CP, Mochizuki M. Vogt-Koyanagi-Harada disease: inquiry into the genesis of a disease name in the historical context of Switzerland and Japan. Int Ophthalmol 2007; 27: 67-79

[20] Koyanagi Y. Poliosis and alopecia associated with idiopathic uveitis. Acta Soc Ophthalmol Jpn 1914; 18: 1188-1192

[21] Harada E. Jikken Ganka Zasshi 1918; 2: 199

[22] Harada E. Beitrag zur klinischen Kenntnis von Michteitriger Choroiditis (choroiditis diffusa acta). Acta Soc Ophthalmol Jpn 1926; 30: 356-378

[23] Koyanagi Y. Dysakusis, Alopecia und Poliosis bei schwerer Uveitis nicht traumatischen Ursprungs. Klin Monatsbl Augenheilkd 1929; 82: 194211

[24] Babel J. Syndrome de Vogt-Koyanagi (Uveite bilateral, poliosis, alopecie, vitiligo et dysacousie). Schweiz Med Wochenschr 1932; 44: 1136-1140

[25] Bruno MG, McPherson SD jr. Harada's disease. Am J Ophthalmol 1949; 32: $513-522$

[26] Gocho K, Kondo I, Yamaki K. Identification of autoreactive T cells in VogtKoyanagi-Harada disease. Invest Ophthalmol Vis Sci 2001; 42: 20042009

[27] Damico FM, Cunha-Neto E, Goldberg AC et al. T-cell recognition and cytokine profile induced by melanocyte epitopes in patients with HLADRB1*0405-positive and -negative Vogt-Koyanagi-Harada uveitis. Invest Ophthalmol Vis Sci 2005; 46: 2465-2471

[28] Sugita S, Takase $H$, Taguchi $C$ et al. Ocular infiltrating CD4+ T cells from patients with Vogt-Koyanagi-Harada disease recognize human melanocyte antigens. Invest Ophthalmol Vis Sci 2006; 47: 2547-2554 
[29] Yokoyama MM, Matsui Y, Yamashiroya HM et al. Humoral and cellular immunity studies in patients with Vogt-Koyanagi-Harada syndrome and pars planitis. Invest Ophthalmol Vis Sci 1981; 20: 364-370

[30] Tran VT, Auer C, Guex-Crosier Y et al. Epidemiological characteristics of uveitis in Switzerland. Int Ophthalmol 1994; 18: 293-298

[31] Ohno S, Char DH, Kimura S] et al. Vogt-Koyanagi-Harada syndrome. Am J Ophthalmol 1977; 83: 735-740

[32] Murakami S, Inaba Y, Mochizuki M et al. A nationwide survey on the occurrence of Vogt-Koyanagi-Harada disease in Japan. Jpn J Ophthalmol 1994; 38: 208-213

[33] Mantovani A, Resta A, Herbort CP et al. Work-up, diagnosis and management of acute Vogt-Koyanagi-Harada disease: a case of acute myopization with granulomatous uveitis. Int Ophthalmol 2007; 27: 105-115

[34] Sugiura S. Vogt-Koyanagi-Harada disease. Jpn J Ophthalmol 1978; 22: 935

[35] Snyder DA, Tessler HH. Vogt-Koyanagi-Harada syndrome. Am J Ophthalmol 1980; 90: 69-75

[36] Read RW, Holland GN, Rao NA et al. Revised diagnostic criteria for VogtKoyanagi-Harada disease: report of an international committee on nomenclature. Am J Ophthalmol 2001; 131: 647-652

[37] Herbort CP jr., Abu El Asrar AM, Takeuchi M et al. Catching the therapeutic window of opportunity in early initial-onset Vogt-Koyanagi-Harada uveitis can cure the disease. Int Ophthalmol 2018. doi:10.1007| s10792-018-0949-4

[38] Chee SP, Chan SN, Jap A. Comparison of Enhanced Depth Imaging and Swept Source Optical Coherence Tomography in Assessment of Choroidal Thickness in Vogt-Koyanagi-Harada Disease. Ocul Immunol Inflamm 2017; 25: 528-532

[39] Khairallah AS. Headache as an initial manifestation of Vogt-KoyanagiHarada disease. Saudi J Ophthalmol 2014; 28: 239-242

[40] Kosma KK, Kararizou E, Markou I et al. Headache as a first manifestation of Vogt-Koyanagi-Harada disease. Med Princ Pract 2008; 17: 253-254

[41] Allegri P, Rissotto R, Herbort CP et al. CNS diseases and uveitis. J Ophthalmic Vis Res 2011; 6: 284-308

[42] Yang P, Ren Y, Li B et al. Clinical characteristics of Vogt-Koyanagi-Harada syndrome in Chinese patients. Ophthalmology 2007; 114: 606-614

[43] Noguchi Y, Nishio A, Takase $\mathrm{H}$ et al. Audiovestibular findings in patients with Vogt-Koyanagi-Harada disease. Acta Otolaryngol 2014; 134: 339344

[44] Fang W, Zhou H, Yang $P$ et al. Longitudinal quantification of aqueous flare and cells in Vogt-Koyanagi-Harada disease. $\mathrm{Br}$ J Ophthalmol 2008; 92: 182-185

[45] Keino H, Goto H, Usui M. Sunset glow fundus in Vogt-Koyanagi-Harada disease with or without chronic ocular inflammation. Graefes Arch Clin Exp Ophthalmol 2002; 240: 878-882

[46] Keino $\mathrm{H}$, Goto $\mathrm{H}$, Mori $\mathrm{H}$ et al. Association between severity of inflammation in CNS and development of sunset glow fundus in Vogt-KoyanagiHarada disease. Am J Ophthalmol 2006; 141: 1140-1142

[47] Abu El-Asrar AM, Hemachandran S, Al-Mezaine HS et al. The outcomes of mycophenolate mofetil therapy combined with systemic corticosteroids in acute uveitis associated with Vogt-Koyanagi-Harada disease. Acta Ophthalmol 2012; 90: e603-e608

[48] Bacsal K, Wen DS, Chee SP. Concomitant choroidal inflammation during anterior segment recurrence in Vogt-Koyanagi-Harada disease. Am J Ophthalmol 2008; 145: 480-486

[49] Wu L, Evans T, Saravia M et al. Intravitreal bevacizumab for choroidal neovascularization secondary to Vogt-Koyanagi-Harada syndrome. Jpn J Ophthalmol 2009; 53: 57-60

[50] Moorthy RS, Mermoud A, Baerveldt G et al. Glaucoma associated with uveitis. Surv Ophthalmol 1997; 41: 361-394

[51] Herbort CP. Fluorescein and indocyanine green angiography for uveitis. Middle East Afr J Ophthalmol 2009; 16: 168-187
[52] Bouchenaki N, Herbort CP. The contribution of indocyanine green angiography to the appraisal and management of Vogt-Koyanagi-Harada disease. Ophthalmology 2001; 108: 54-64

[53] Bouchenaki N. Herbort CP. Indocyanine green angiography guided management of vogt-koyanagi-harada disease. J Ophthalmic Vis Res 2011; 6: 241-248

[54] Balci O, Gasc A, Jeannin B et al. Enhanced depth imaging is less suited than indocyanine green angiography for close monitoring of primary stromal choroiditis: a pilot report. Int Ophthalmol 2017; 37: 737-748

[55] Yuzawa M, Kawamura A, Matsui M. Indocyanine green video-angiographic findings in Harada's disease. Jpn J Ophthalmol 1993; 37: 456466

[56] Harada T, Kanbara Y, Takeuchi T et al. Exploration of Vogt-KoyanagiHarada syndrome by infrared choroidal angiography with indocyanine green. Eur J Ophthalmol 1997; 7: 163-170

[57] Herbort CP, Mantovani A, Bouchenaki N. Indocyanine green angiography in Vogt-Koyanagi-Harada disease: angiographic signs and utility in patient follow-up. Int Ophthalmol 2007; 27: 173-182

[58] Miyanaga M, Kawaguchi T, Miyata K et al. Indocyanine green angiography findings in initial acute pretreatment Vogt-Koyanagi-Harada disease in Japanese patients. Jpn J Ophthalmol 2010; 54: 377-382

[59] Abouammoh MA, Gupta V, Hemachandran S et al. Indocyanine green angiographic findings in initial-onset acute Vogt-Koyanagi-Harada disease. Acta Ophthalmol 2016; 94: 573-578

[60] Liu XY, Peng XY, Wang S et al. Features of optical coherence tomography for the diagnosis of Vogt-Koyanagi-Harada disease. Retina 2016; 36: 2116-2123

[61] Nakayama M, Keino H, Okada AA et al. Enhanced depth imaging optical coherence tomography of the choroid in Vogt-Koyanagi-Harada disease. Retina 2012; 32: 2061-2069

[62] Nakai K, Gomi F, Ikuno Y et al. Choroidal observations in Vogt-KoyanagiHarada disease using high-penetration optical coherence tomography. Graefes Arch Clin Exp Ophthalmol 2012; 250: 1089-1095

[63] Kitaichi N, Matoba H, Ohno S. The positive role of lumbar puncture in the diagnosis of Vogt-Koyanagi-Harada disease: lymphocyte subsets in the aqueous humor and cerebrospinal fluid. Int Ophthalmol 2007; 27: 97103

[64] Herbort CP jr., Abu El Asrar AM, Yamamoto JH et al. Reappraisal of the management of Vogt-Koyanagi-Harada disease: sunset glow fundus is no more a fatality. Int Ophthalmol 2017; 37: 1383-1395

[65] Kawaguchi T, Horie S, Bouchenaki N et al. Suboptimal therapy controls clinically apparent disease but not subclinical progression of Vogt-Koyanagi-Harada disease. Int Ophthalmol 2010; 30: 41-50

[66] Zmuda M, Tiev KP, Knoeri ] et al. Successful use of infliximab therapy in sight-threatening corticosteroid-resistant Vogt-Koyanagi-Harada disease. Ocul Immunol Inflamm 2013; 21: 310-316

[67] Elahi SG, Gasc K, Jeannin A et al. Sensitivity of ICGA compared to FA and EDI-OCT during tapering and fine-tuning of therapy in primary stromal choroiditis: a case series. J Curr Ophthalmol 2018. doi:10.1016/j.joco. 2018.12.006

[68] Ryan S], Maumenee AE. Birdshot retinochoroidopathy. Am J Ophthalmo 1980; 89: 31-45

[69] Gass JD. Vitiliginous chorioretinitis. Arch Ophthalmol 1981; 99: 17781787

[70] Nussenblatt RB, Mittal KK, Ryan S et al. Birdshot retinochoroidopathy associated with HLA-A29 antigen and immune responsiveness to retinal S-antigen. Am J Ophthalmol 1982; 94: 147-158

[71] LeHoang P, Ozdemir N, Benhamou A et al. HLA-A29.2 subtype associated with birdshot retinochoroidopathy. Am J Ophthalmol 1992; 113: 33-35 
[72] Papadia M, Herbort CP. Reappraisal of birdshot retinochoroiditis (BRC): a global approach. Graefes Arch Clin Exp Ophthalmol 2013; 251: 861869

[73] Herbort CP, Probst K, Cimino L et al. Differential inflammatory involvement in retina and choroid in birdshot chorioretinopathy. Klin Monatsbl Augenheilkd 2004; 221: 351-356

[74] Gaudio PA, Kaye DB, Crawford JB. Histopathology of birdshot retinochoroidopathy. $\mathrm{Br}$ J Ophthalmol 2002; 86: 1439-1441

[75] Matsumoto Y, Haen SP, Spaide RF. The white dot syndromes. Compr Ophthalmol Update 2007; 8: 179-200, discussion 203-204

[76] Papadia M, Herbort CP jr. New concepts in the appraisal and management of birdshot retinochoroiditis, a global perspective. Int Ophthalmol 2015; 35: 287-301

[77] Guex-Crosier Y, Herbort CP. Prolonged retinal arterio-venous circulation time by fluorescein but not by indocyanine green angiography in birdshot chorioretinopathy. Ocul Immunol Inflamm 1997; 5: 203-206

[78] Papadia M, Jeannin B, Herbort CP. OCT findings in birdshot chorioretinitis: a glimpse into retinal disease evolution. Ophthalmic Surg Lasers Imaging 2012; 43 (Suppl. 6): S25-S31

[79] Baarsma GS, Priem HA, Kijlstra A. Association of birdshot retinochoroidopathy and HLA-A29 antigen. Curr Eye Res 1990; 9 (Suppl.): 63-68

[80] Tran VT, Auer C, Guex-Crosier Y et al. Epidemiology of uveitis in Switzerland. Ocul Immunol Inflamm 1994; 2: 169-176

[81] Minos E, Barry RJ, Southworth S et al. Birdshot chorioretinopathy: current knowledge and new concepts in pathophysiology, diagnosis, monitoring and treatment. Orphanet J Rare Dis 2016; 11: 61

[82] Levinson RD, Brezin A, Rothova A et al. Research criteria for the diagnosis of birdshot chorioretinopathy: results of an international consensus conference. Am J Ophthalmol 2006; 141: 185-187

[83] Knecht PB, Papadia M, Herbort CP. Granulomatous keratic precipitates in birdshot retinochoroiditis. Int Ophthalmol 2013; 33: 133-137

[84] Herbort CP jr., Pavesio C, LeHoang P et al. Why birdshot retinochoroiditis should rather be called 'HLA-A29 uveitis'? Br J Ophthalmol 2017; 101: 851-855

[85] de Courten C, Herbort CP. Potential role of computerized visual field testing for the appraisal and follow-up of birdshot chorioretinopathy. Arch Ophthalmol 1998; 116: 1389-1391

[86] Cimino L. Importance of visual field testing in the functional evaluation and follow-up of birdshot chorioretinopathy. Ophthalmic Res 2002; 34 : 141

[87] Arya B, Westcott M, Robson AG et al. Pointwise linear regression analysis of serial Humphrey visual fields and a correlation with electroretinography in birdshot chorioretinopathy. Br J Ophthalmol 2015; 99: 973-978

[88] Guex-Crosier Y, Pittet N, Herbort CP. Sensitivity of laser flare photometry to monitor inflammation in uveitis of the posterior segment. Ophthalmology 1995; 102: 613-621

[89] Knecht PB, Papadia M, Herbort CP jr. Early and sustained treatment modifies the phenotype of birdshot retinochoroiditis. Int Ophthalmol 2014; 34: 563-574

[90] Balci O, Jeannin B, Herbort CP jr. Contribution of dual fluorescein and indocyanine green angiography to the appraisal of posterior involvement in birdshot retinochoroiditis and Vogt-Koyanagi-Harada disease. Int Ophthalmol 2018; 38: 527-539
[91] Priem HA, De Rouck A, De Laey J] et al. Electrophysiologic studies in birdshot chorioretinopathy. Am J Ophthalmol 1988; 106: 430-466

[92] Holder GE, Robson AG, Pavesio C et al. Electrophysiological characterisation and monitoring in the management of birdshot chorioretinopathy. $\mathrm{Br}$ J Ophthalmol 2005; 89: 709-718

[93] Fardeau C, Herbort CP, Kullmann N et al. Indocyanine green angiography in birdshot chorioretinopathy. Ophthalmology 1999; 106: 1928 1934

[94] Tugal-Tutkun I, Herbort CP, Khairallah M. Scoring of dual fluorescein and ICG inflammatory angiographic signs for the grading of posterior segment inflammation (dual fluorescein and ICG angiographic scoring system for uveitis). Int Ophthalmol 2010; 30: 539-552

[95] Skvortsova N, Gasc A, Jeannin B et al. Evolution of choroidal thickness over time and effect of early and sustained therapy in birdshot retinochoroiditis. Eye (Lond) 2017; 31: 1205-1211

[96] Phasukkijwatana N, lafe N, Sarraf D. Optical Coherence Tomography Angiography of A29 Birdshot Chorioretinopathy Complicated by Retinal Neovascularization. Retin Cases Brief Rep 2017; 11 (Suppl. 1): S68$\mathrm{S} 72$

[97] Pohlmann D, Macedo S, Stubiger N et al. Multimodal Imaging in Birdshot Retinochoroiditis. Ocul Immunol Inflamm 2017; 25: 621-632

[98] de Carlo TE, Bonini Filho MA, Adhi M et al. Retinal and Choroidal Vasculature in Birdshot Chorioretinopathy Analyzed Using Spectral Domain Optical Coherence Tomography Angiography. Retina 2015; 35: 23922399

[99] Rothova A, Berendschot TT, Probst K et al. Birdshot chorioretinopathy: long-term manifestations and visual prognosis. Ophthalmology 2004; 111: 954-959

[100] Levinson RD, Gonzales CR. Birdshot retinochoroidopathy: immunopathogenesis, evaluation, and treatment. Ophthalmol Clin North Am 2002; 15: 343-350, vii

[101] Becker MD, Wertheim MS, Smith JR et al. Long-term follow-up of patients with birdshot retinochoroidopathy treated with systemic immunosuppression. Ocul Immunol Inflamm 2005; 13: 289-293

[102] Vitale AT, Rodriguez A, Foster CS. Low-dose cyclosporine therapy in the treatment of birdshot retinochoroidopathy. Ophthalmology 1994; 101: $822-831$

[103] Godel V, Baruch E, Lazar M. Late development of chorioretinal lesions in birdshot retinochoroidopathy. Ann Ophthalmol 1989; 21: 49-52

[104] Kaplan HJ, Aaberg TM. Birdshot retinochoroidopathy. Am J Ophthalmol 1980; 90: 773-782

[105] Christmas NJ, Oh KT, Oh DM et al. Long-term follow-up of patients with serpinginous choroiditis. Retina 2002; 22: 550-556

[106] Le Hoang P, Girard B, Deray G et al. Cyclosporine in the treatment of birdshot retinochoroidopathy. Transplant Proc 1988; 20 (3 Suppl. 4): $128-130$

[107] Leder HA, Galor A, Thorne JE et al. Disappearance of classic birdshot spots after immunosuppression with tacrolimus and mycophenolate mofetil. Br J Ophthalmol 2008; 92: 291

[108] Cao JH, Silpa-Archa S, Freitas-Neto CA et al. Birdshot chorioretinitis lesions on indocyanine green angiography as an indicator of disease activity. Retina 2016; 36: 1751-1757 